\title{
Urban transport planning and access inequalities: a tale of two Colombian cities
}

\author{
Julian Arellana ${ }^{\mathrm{a}}$, Daniel Oviedo ${ }^{\mathrm{b}}$, Luis A. Guzman ${ }^{\mathrm{c}}$, Vilma Alvarez \\ ${ }^{a}$ Universidad del Norte, Barranquilla, Colombia \\ bUniversity College London, London, UK \\ ${ }^{c}$ Universidad de Los Andes, Bogotá D.C., Colombia \\ Received 9 June 2020, Revised 31 August 2020, Accepted 3 September 2020, Available online 11 \\ September 2020.
}

\begin{abstract}
Accessibility inequalities are a common trait of many Global South cities. Such inequalities are often the result of urban development trajectories and inherited practices of transport planning marked by spatial segregation and decades of car-centred development. This situation, repeated across Latin American cities, tends to affect mostly the poor in the urban peripheries. Despite available evidence of access inequalities on a case-to-case basis, comparative evidence across cities within the same region is still limited. Our paper addresses this gap by deploying a comparative accessibility assessment of inequalities in accessibility in the two Colombian cities of Bogotá and Barranquilla. Our comparison suggests that by following similar patterns of urban transport development, Bogotá and Barranquilla have reached similar accessibility and affordability patterns. Wealthier areas benefit from the triad of better transport coverage, proximity to opportunities, and higher purchasing power, while the poor in both cities face deep affordability and spatial segregation problems. Despite their similarities, our analysis reveals the effects of long-term decision-making in the number of opportunities which can be reached by different transport modes and population segments. Accessibility per capita in public transport is higher in Bogotá than in Barranquilla, and vice versa in private vehicles. These results are consistent with nearly a decade of implementation of different urban transport policies in both cities, which in Bogotá have been more publictransport-oriented than in Barranquilla. Findings also suggest that public transport-related policies can contribute to redefining urban trajectories, as both cities have experienced demographic and urban footprint increases in years. Similarities and differences in spatial and economic dimensions of accessibility serve as a mirror against which we assess transport's role in urban equality in similar global south cities. The discussion in this paper can be helpful to decision-makers as it recalls that some urban and transport policies and investments may have undesired long-term impacts in urban growth and access equality across the city.
\end{abstract}

Keywords: accessibility, urban trajectories, horizontal equality, vertical equality, affordability, Barranquilla, Bogota

\section{Introduction}

During recent years, equality and social inclusion have become relevant research topics in transport and urban planning studies, recognising the social role of urban transport in social, economic and urban development, while challenging the structural inequalities, 
understood as the gaps in the ability of individuals and social groups sharing differences of gender, age, ethnicity, class and disability to reach essential opportunities, which are associated with transport's development patterns (Gwilliam, 2013; Hickman et al., 2015; Levy \& Dávila, 2017). In recent research, accessibility has been hailed as a way to challenge utilitarian approaches to transport planning while increasing equality in cities, with some authors suggesting that despite many decades of accessibility research, the concept is finally permeating the mainstream of transport planning and decision-making (Ferreira \& Papa, 2020; Handy, 2020; Levine, 2020). The central idea is supported by several ethical theories that suggests equalizing the relative level of accessibility between different social groups instead of maximising the sum of benefits for all people (van Wee \& Geurs, 2011). Among this theories, the egalitarian approach considers giving people the same access to opportunities (Lucas et al., 2016), while the Rawlsian theory believes that access to opportunities should be planned accounting for people needs (van Wee \& Geurs, 2011). Accessibility as a tool for building more equitable cities claims added relevance and timeliness in Global South contexts, where the absence of adequate land management policies and poor transport planning processes have triggered social, spatial and economic inequalities among urban populations marked by structural and selective marginalisation of particular social groups (Pereira, Schwanen, \& Banister, 2017; Uteng \& Lucas, 2017; Vecchio, Tiznado-Aitken, \& Hurtubia, 2020). Conversely, Global South cities are in a position where despite the consolidation of unequal and exclusionary patterns of urban and transport development, lower motorisation rates in comparison with cities in more industrialised settings, and renewed local and global commitments to sustainable transport can serve as opportunities to redefine urban trajectories towards more inclusive and accessible cities (Jones, 2016; Ortúzar, 2019; Venter, Mahendra, Hidalgo, 2019; Woolf \& Joubert, 2013).

This paper tests the potential of accessibility measures as a mechanism to critically assess the effects of different urban trajectories (Levy, Allen, Castán Broto, \& Westman, 2017; Uteng \& Lucas, 2017), comparing seemingly similar urban contexts in the same country in terms of their accessibility distribution. Such trajectories are defined in this paper as the city's patterns of spatial, socio-economic and functional growth, which is influenced by practices of urbanisation and planning (e.g. developing along public transport corridors), socioeconomic differences and social positions of the population, and the politics of urban and transport development (Banister \& Hickman, 2013; Levy et al., 2017; Uteng \& Lucas, 2017). Specifically, the paper discusses two distinct, albeit simplified, trajectories as identified by Jones (2016): car-centred and public-transport-centred trajectories, which are reflected by accessibility analysis focused on the same transport modes.

The paper provides empirical evidence from a comparative accessibility assessment of two Colombian cities, Bogotá and Barranquilla, to enact more profound reflections about the social consequences of transport policy and decision-making. By doing so, the paper aligns with research that positions accessibility planning as a viable mechanism for redistribution and social assessment of urban transport (J P Bocarejo \& Oviedo, 2012; Cui et al., 2020; Curtis \& Scheurer, 2010). In particular, we make use of potential accessibility and affordability measures to highlight similarities and differences in the effects of different patterns of transport development. We include affordability measures in the analysis, parting from the recognition that, for a majority of urban citizens in the Global South, transport costs 
represent a heavy economic burden and a barrier to accessibility driven by differences in location and socio-economic characteristics (Dewita et al., 2018). The paper builds on similar land-use and transport datasets for both cities to conduct the analysis, leading to reliable indicators that inform its conclusions.

The paper also embeds itself in global policy objectives targeting equal accessibility to opportunities and reducing inequalities as a central element in achieving sustainable mobility (Ford et al., 2015). Such high-level policy objectives are best exemplified by the United Nations' Sustainable Development Goals (SDG), particularly SDG11 of Sustainable Cities and Communities, and SDG10, Reduced Inequalities. In this context, it is important to acknowledge that accessibility has not only permeated the evolution of research, but also that discourses and practice of urban transport have adopted and given relevance to the concept and its associated methods (Hackl, 2018; Malekzadeh \& Chung, 2019; Niehaus et al., 2016). Our paper adds to these debates by highlighting the structural differences and challenges for accessibility in cities experiencing different urban trajectories and approaches to transport development, particularly in the last decade.

The remainder of the paper is organised as follows. Section 2 presents a short review of accessibility, affordability, and social equality. Section 3 describes the methodology to calculate all measures used throughout the paper. Section 4 contextualises the cities and their urban transport trajectories. Section 5 explains the results and Section 6 presents the conclusions and opportunities for further research on this topic.

\section{Accessibility, affordability and inequality}

Definitions and measurements of accessibility have grown rapidly, particularly since the early 2000s (Geurs \& van Wee, 2004; Levine, 2020). Bocarejo \& Oviedo (2012) define accessibility as the capacity to access opportunities depending on the transport supply and land-use characteristics, while recognising that not all individuals are in the same social position to make use of such systems or access spatially scattered opportunities (Levy, 2013). Following Geurs \& van Wee (2004), the concept refers to the relationship between activity locations and the transport system that allows the movement of people between zones in a specific transport mode or combination, at specific times, in order to achieve their activities.

Even in its most common definition, accessibility captures the intersecting relationships between land-use, transport, time, and individual characteristics (Geurs \& van Wee, 2004). This places accessibility ahead mobility-centred approaches to transport planning and assessment in terms of complexity and distributional value, as it considers the spatial and functional context in which a diverse population interacts with the city's transport systems (Ferreira \& Papa, 2020). By considering a temporal and individual dimension, the concept of accessibility also recognises the dynamic nature of urban mobility and the role of social positions in determining individual and collective capacities to make use of both transport systems and opportunities distributed in space.

Considering the above, it is no wonder accessibility has gained importance in the transport and urban planning. The multidimensionality of the concept, coupled with easily 
operationalizable measures -even in contexts challenged by limited data and resources availability-, has made it attractive for research and practice that a few decades ago were fixated on mainly assessing travel times and travel speeds (Dimitriou \& Gakenheimer, 2011; Ortuzar \& Willumsen, 2011; Wu \& Levinson, 2020). Modern accessibility research includes a broader set of perspectives of transport systems, with a larger emphasis on its links with reliability, sustainability and equality (Benevenuto \& Caulfield, 2019; Bertolini et al., 2005; Bocarejo \& Oviedo, 2012; Cervero et al., 1999; Curtis \& Scheurer, 2010, 2015; Oviedo \& Guzman, 2020; Weiss et al., 2018).

Focusing on the different components of accessibility, both individually and collectively, provides researchers with an effective lens to understand urban trajectories. For instance, compact and diverse land-use planning can lead to more equitable distribution of opportunities and shorter travel distances and costs, increasing accessibility levels (Geurs \& van Wee, 2004; Singh et al., 2017; van Wee, 2011). Moreover, the investment in highcapacity transport infrastructure, either for public or private operation, can lock cities in trajectories of urban development that foster specific transport modes and more disperse or compact land-uses, influencing the overall accessibility of the population (Cervero, 2013; Cervero \& Dai, 2014; Kloosterman \& Lambregts, 2001; Automobility, 2015). Accessibility can also inform distributional analysis of the effects of such patterns of urban and transport development, being frequently used in recent years as a social indicator to establish how different social groups can or not gain access to opportunities (Foth et al., 2013). Such differentiated accessibility wins and losses have also been associated with economic development and quality of life (Ford et al., 2015; Jones \& Lucas, 2012; Weiss et al., 2018). Accessibility allows for assessing policies and investments in terms of the extent to which they improve equality in urban areas (Lucas et al., 2016; Niehaus et al., 2016). Such equality can be differentiated between horizontal and vertical.

Also, the distribution of accessibility between different social groups and urban space is crucial to more informed urban transport research (Guzman et al., 2017). From this, differences in accessibility and gaps between population groups can be estimated. This gaps can measured using the concept of horizontal equality, which refers to the uniform distribution of the benefits obtained by accessibility gains by all individuals, considering that people have the same needs (Camporeale et al., 2017; Guzman et al., 2017). The literature recognises that this measure indicates how gaps are reduced or exacerbated by policies or projects and how benefits are spatially and socially distributed (Curl, 2018). Accessibility inequalities have caused patterns of spatial and social segregation due to high travel times and transport costs experienced by some groups of the population. Transport investments and historical urban development trajectories in cities of the Global South have concentrated economic activities in specific areas of the city, leading to land value increases and forcing people who cannot afford housing costs to locate in peripheral areas or moving to social housing projects. Then, people who live at urban fringes, traditionally the poorest zones, are the ones who experience the greatest disadvantage in transport, leading to these vulnerable people to have reduced accessibility to goods and services (Lucas, 2012).

In current practice at research, academic and public agencies, accessibility measures take many scales and forms and are used according to the intended goal. Although this gives an idea about the differences in access, it is necessary to consider the existence of horizontal 
and vertical inequalities. In Latin America, one of the most unequal regions in the world (Bárcena \& Byanyima, 2016; Simson \& Savage, 2020), some studies report that low income and socially vulnerable populations also experience adverse effects due to low-quality transport, having longer travel times and higher generalised travel costs to access opportunities to increase their economic, human and social capital (Guzman, Oviedo, \& Rivera, 2017; Oviedo \& Guzman, 2020). Transport costs are, from an accessibility perspective, both a driver of exclusion, segregation and inaccessibility, and a consequence of urban trajectories that have pushed low-income and other vulnerable populations to areas with poorer accessibility (Guzman \& Oviedo, 2018), resulting in a self-reinforcing cycle of disadvantage. A recent study in the context of Bogotá, however, suggests that although access to mandatory opportunities is influenced by the city's centralised urban structure, non-mandatory access follows a different pattern, with more local opportunities and nonmotorised access playing a relevant role in a more equitable distribution (Oviedo \& Guzman, 2020).

The distribution of accessibility by income groups is an example of a measure of vertical equality. Vertical equality refers to the distribution of impacts between groups that have different abilities and needs (Litman, 2002). Considering that the cost of transport represents a considerable household expense and that it profoundly affects the lowest income people, it is critical to consider the affordability concept to evaluate how accessibility is distributed among different groups. The affordability concept allows evaluating policies (Gandelman et al., 2019), vertical equality, as well to decide which zones need more investment (Falavigna \& Hernandez, 2016; Guzman \& Oviedo, 2018; Venter, 2011). The affordability and therefore accessibility measurements can help decision-makers to intervene in public transport policies making it inclusive systems. Guzman et al., (2017) found strong empirical evidence about uneven distributional effects of the socio-spatial and economic structure in Bogotá among socio-economic groups and transport users. Venter (2011) found that low and medium-income people in South Africa spend more from their incomes to complete their mandatory trips than other wealthier groups. This author recommended using the affordability concept and transport expenditures in order to improve the quality of life for the most vulnerable people through policies to minimise their travel cost.

Different indexes that are commonly used to assess income inequalities can be adapted to provide evidence on the distributional effects of accessibility. The Lorenz curves considering population and the Gini coefficients are popular approaches for these purposes (Guzman et al., 2017). The Gini index ranges from 0 to 1 , where zero corresponds to perfect equality (i.e. everyone experiences the same accessibility) and one refers to perfect inequality (i.e. one individual has all the accessibility, while the rest none). However, the Gini Index, when used to measure income inequalities, has been criticized because it suffer significant changes if an income variation occurs. Meanwhile, according to Dayioğlu \& Başlevent (2006) the Atkinson index can overcome some of the drawbacks of the Gini index. The Atkinson index is useful in determining which end of the distribution contributed most to the observed inequality. However, this measure experiences significant changes with income transfers in the lower tail of the income distribution, taking place easily when higher values of the aversion parameter of inequality is presented. 
Also, according to Palma (2006), the Gini index only shows the inequality existing between the incomes of the richest population (10\% of the population) and poorest population ( $40 \%$ of the population), leaving out the remaining $50 \%$ of the population which could have homogeneity in their income distribution. Thereby, the Gini index will only be useful to measure the whole income inequality. Then, a measure such as the Palma ratio can be adapted to measure the accessibility concentration properly. In this case, the Palma ratio is calculated as the accessibility experienced by the $10 \%$ of the richest population divided by the accessibility experienced by the $40 \%$ of the poorest population (Cobham et al., 2016).

According to Eliazar \& Sokolov (2010), the Pietra index could represent the egalitarianism approach. This measure results of maximizing the distance between the Lorenz Curve and the perfect equality curve. The Pietra index can be interpreted as the average surplus of the random variable over its mean. Similarly to the Gini index, the Pietra index ranges from 0 to 1 . The closer to zero the more egalitarian society is. On the other hand, if the index takes a value of 1 , then there is a non-egalitarian society. Eliazar \& Sokolov (2010) mention that Gini index is useful to measure the difference between two individuals of the population, while the Pietra index is useful to measure the deviation of an individual from the population mean.

Finally, other option to assess inequalities could be the Theil index. This index is categorized as an entropy index, which takes a 0 value when an equal distribution is presented. The Theil index does not have an upper boundary, because it can tend to infinity (Ono et al., 2010). Cowell (2000) applied the Theil index to measure inequalities, identifying that this measure can be decomposed in groups and then obtain the index as the weighted sum of each group.

The literature on accessibility in low-income and developing contexts points to inequalities in the distribution of access influenced by long-term patterns of urban development that are segregated, monocentric and that are influenced by an uneven distribution of transport connectivity. Affordability is presented as a significant constraint in the definition of individual and collective accessibility, particularly across low-income populations, with more recent research unpacking differences by gender and other social identities. However, perhaps more than in cities in the Global North, evidence from rapidly growing cities suggests that understanding the complex interrelations between urban development trajectories and the consequent gaps in accessibility can shed light on the role of standardised policies for transport and land use. It is possible to infer some commonalities across cities in the Global South and, in particular, Latin American cities. The latter exhibit more convenient conditions for the high and middle-income near well-defined city centres, while middle-low and low-income populations have lower access to both transport and opportunities at a higher relative cost. Despite these generalizable observations, there is a lack of explicit comparisons in the literature using the same metrics to draw conclusions on the manifestation of access inequalities in different urban environments. Moreover, most research about accessibility in urban contexts in Latin America and the Global South has not directly engaged with the notion of development trajectories or the explicit policies that may have an influence in the components of accessibility defined in the literature (Geurs \& van Wee, 2004). We address such gaps through the comparative analysis of accessibility and its links with policies and practices that have defined specific urban development trajectories 
in both cities, leading to the manifested inequalities that can be mapped with available data in the two cities selected for analysis.

\section{Methodology}

In order to determine the spatial and social distribution of accessibility and affordability levels in Barranquilla and Bogotá, we analysed the travel patterns of their inhabitants. We used information from household origin-destination surveys issued in 2011 in Barranquilla and Bogotá. For both cities, the analysis only included study- and work-trips-related made by private motorised vehicles and public transport. We decided to use the 2011 survey since it corresponds to the last representative household origin-destination survey collected for developing a master mobility plan for Barranquilla. Therefore, we used the Bogotá survey from the same year for comparative purposes.

In this paper, we use the accessibility definition given by Geurs \& van Wee (2004) that measures the potential degree of connection between two spots located using a gravitational form. The gravitational form measures the potential access to opportunities in all destination areas $j$ from an origin zone $i$. Gravitational models allow representing the decrease of potential access to opportunities to a particular destination area $j$ due to an increase in costs for accessing to the same area. Then, the accessibility of the zone $i$, denoted as $A_{i}$, is a function of the opportunities that can be accessed from that zone to all destination zones $j$ $\left(O_{j}\right)$. Equation 1 describes this gravitational expression, where generalised travel costs from origin $i$ to destination $j$ are represented by $C_{i j}$, and a calibration parameter $\left(\beta_{i}\right)$ is included to capture cost sensibility. The $m$ subscript indicates the transport mode (i.e. car and public transport).

$A_{i}^{m}=\sum_{j=1}^{n} O_{j} e^{\left(-\beta_{i}{ }^{m} C_{i j}{ }^{m}\right)}$

We obtained the generalised travel cost by combining average travel time $\left(T T_{i j}\right)$, walking time $\left(W A_{i j}\right)$, waiting time $\left(W N_{i j}\right)$, and operational cost $\left(C o p_{i j}\right)$. We decided to express the generalised cost in terms of minutes, as shown in Equation 2. To allow combining all times and costs, we included $f_{c}$ and $f_{e}$ factors to convert walking and waiting times to equivalent travel time. Also, we considered a travel value of time (VOT) to convert cost to travel time.

$$
C_{i j}^{m}=T T_{i j}^{m}+f_{C} W A_{i j}^{m}+f_{e} W N_{i j}^{m}+\frac{\operatorname{Cop}_{i j}^{m}}{V O T^{m}}
$$

For Barranquilla, we obtained the data from the travel diaries of the 2011 origindestination survey collected for the mobility plan of the city (Consorcio TPD-Epypsa, 2012). The operational cost considers cost per kilometre travelled, parking cost, and fare in the case of public transport. Considering that previous studies in Barranquilla report waiting and walking times are worse perceived than travel times, we defined $f_{c}$ equal to 1.5 and $f_{e}$ equal to 3 (Cantillo et al., 2010). The $V O T^{m}$ for private motorised vehicles was $100 \mathrm{COP} / \mathrm{min}$, while for public transport was $40 \mathrm{COP} / \mathrm{min}$, which are in line with values of time for different income groups reported in the latest Barranquilla mobility plan (Consorcio TPD-Epypsa, 2012). We computed operational costs considering $450 \mathrm{COP} / \mathrm{km}$ and distances in $\mathrm{km}$ from 
origin to destination, as reported in the travel diary survey. The public transport fare was in the range of COP 1,300 and 1,400 COP for $2012^{1}$.

For Bogotá, the primary source of information was the 2011 Mobility Survey. This survey was carried out in 16,163 households in the study area. In line with Guzman et al. (2017), the $V O T^{m}$ was $69.6 \mathrm{COP} / \mathrm{min}$ for both transport modes. The public transport fare was in the range of 1,450 COP and 1,700 COP, according to the type of service used. The cheapest fare was associated with regular buses while the most expensive to BRT services. We computed operational costs considering 426.5 COP/ $\mathrm{km}$ and distances in $\mathrm{km}$ obtained from a transport planning model for the Bogotá region. Table 1 presents descriptive statistics of both mobility surveys.

Table 1. Descriptive statistics of survey data

\begin{tabular}{lcc}
\hline & Bogotá & Barranquilla \\
\hline Population (inhabitants) & $6,883,198$ & $1,574,524$ \\
Total trips & $15,349,976$ & $2,207,060$ \\
Total motorized trips & $7,960,133$ & $1,514,002$ \\
Total non-motorized trips & $7,389,843$ & 693,058 \\
Survey sample size (household surveys) & 16,157 & 9,960 \\
Household size (inhabitants/household) & 3.2 & 4.0 \\
Car-ownership (vehicles per thousand inhabitants) & 136 & 75 \\
Daily trips per inhabitant & 2.2 & 1.4 \\
Average travel time (minutes) & 39.5 & 31.7 \\
Average motorized travel time (minutes) & 59.3 & 39.1 \\
Average non-motorized travel time (minutes) & 16.0 & 14.3 \\
\hline
\end{tabular}

We estimated parameters $\beta_{i}{ }^{m}$ through multiple regression analyses considering Equation 1. We assumed that the total amount of work and study trips per zone $(i)$ and mode $(m)$ in the surveys are an approximation of the zone accessibility value $\left(A_{i}\right)$. We computed potential accessibility per capita for each zone as a measure of horizontal equality, which is the result of dividing potential accessibility by zone population.

Additionally, we estimated the affordability per zone considering each transport mode, using the definition given by Carruthers, Dick, \& Saurkar (2005). Equation 3 shows the definition of an affordability index of the trip costs for the zone $i$ and mode $m$ (i.e. private motorised and public transport).

$A f f_{i}^{m}=\frac{k \times T_{i}^{m} \times E x_{i}^{m}}{h_{o}^{m} \times Y_{i}}$

Where $T_{i}^{m}$ in the equation represents the total amount of trips from the origin zone in a given mode. The variable $E x_{i}^{m}$ refers to the average trip expense per household; while $Y_{i}$ stands for the average household income; and $h_{o}^{m}$ represents the number of households in the zone $i$ that travelled in the mode $m$. Finally, the $k$ factor is used to convert daily trips to a monthly basis. We considered $k$ equal to 22 , which is the average business days in a month. The average income per zone was obtained from official sources, according to socio-

\footnotetext{
${ }^{1}$ The average exchange rate from US dollar (USD) to Colombian Peso (COP) for 2011 was 1805.6
} 
economic strata (SES) level (Table 2). Households income in Colombia tends to correlate with SES, which comes from a system to classify urban population, implemented since the '90s. This stratification system classifies residential areas in groups between 1 and 6, where poorest areas tend to belong to SES 1, and wealthiest to SES 6. This stratification system is commonly used to give crossed subsidies in public services for people with the lowest strata (Cantillo-García et al., 2019). For this study, the lowest income people were associated with SES 1 and 2, the medium-income population with SES 3 and 4, while the wealthiest people with SES 5 and 6.

Table 2. Average income in Barranquilla and Bogotá

\begin{tabular}{cccc}
\hline Income group & SES & Barranquilla & Bogotá \\
\hline Low-income & 1 and 2 & $1,150,676$ COP (637.3 USD) & 948,109 COP (525.1 USD) \\
Medium-income & 3 and 4 & $1,820,135$ COP (1,008.0 USD) & $2,020,636$ COP (1,119.1 USD) \\
High-income & 5 and 6 & $4,055,769$ COP (2,246.2 USD) & $4,116,667$ COP (2,279.9 USD) \\
\hline \multicolumn{5}{c}{ Source: EDUBAR S.A (2012) and Bogotá Mobility Secretary (2011) }
\end{tabular}

Finally, we also developed an equality analysis which is important because accessibility is not the same for all populations, nor is it distributed uniformly in the study areas. To compare the distribution of accessibility levels among the population (horizontal equality) and different socio-economic levels (vertical equality), we rely on to use of Lorenz curves and Gini indexes (Guzman et al., 2017; Lucas et al., 2016).

\section{Examining urban trajectories in Bogotá and Barranquilla}

Barranquilla and Bogotá are two of Colombia's largest cities. Bogotá is the country's capital, the largest urban conurbation in Colombia, and its most important economic engine. Bogotá also has one of the largest population densities in the world, even when compared with urban agglomerations such as Sao Paulo and Mexico City (UN-Habitat, 2014). By 2012, Bogotá had an urban extension of $360 \mathrm{~km}^{2}$ and a population of $6^{\prime} 887,422$ inhabitants. Barranquilla, on the other hand, is the most populous and sprawled city on the Colombian north coast but the fourth in terms of the population considering the whole country. In 2012, Barranquilla had an extension of $154 \mathrm{~km}^{2}$, and a population of 1'200,820 people. Geographically, Barranquilla forms a conurbation with Soledad, the seventh most populated city in the country. Soledad had an extension of $67 \mathrm{~km}^{2}$ and 550,875 inhabitants for the same year. In this article, the Barranquilla region refers to the conurbation of Barranquilla and Soledad. In terms of extension and population, Bogotá has 2.77 times more area than the Barranquilla region, while 5.74 times its population.

Both Bogotá and Barranquilla have followed urban development trajectories marked by rapid demographic and spatial growth. According to the Atlas of Urban Expansion for Colombia (Sholomo et al., 2017), increase in the urban footprint in the nearly 25 years between 1990 and 2015 has been higher for Barranquilla than for Bogotá. The urban footprint of Barranquilla increased by 53\% in the 1991-2014 period, while Bogotá's increased by $43 \%$ in the 1991-2015 period, as shown in Figure 1. Barranquilla's trajectory has been marked by urban transport policies that have favoured car-based mobility and land-use plans and markets that have profited from developing land in the northern and southern outskirts to 
respond to increasing demand for both high and low-income housing. While Bogotá experienced both demographic increases and the physical expansion of its perimeter, such growth manifested in increases in both population and built-up densities, mostly in proximity to already consolidated corridors of public transport. In Barranquilla, the accessibility gains afforded by mass transit corridors have not been fully captured by the city's land markets and development, leading to a relatively constant density in the proximity to the city's Bus Rapid Transit lines.

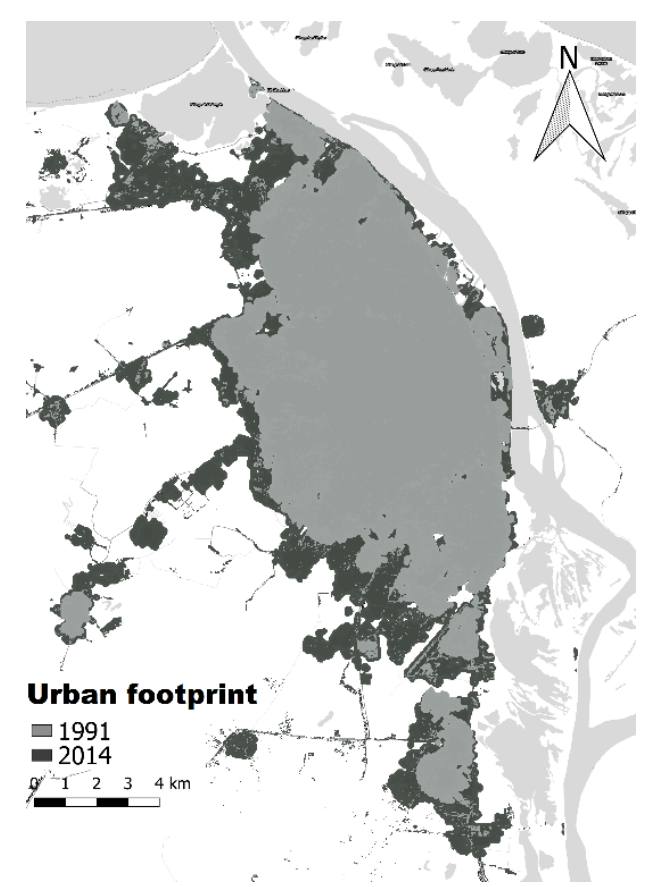

Barranquilla

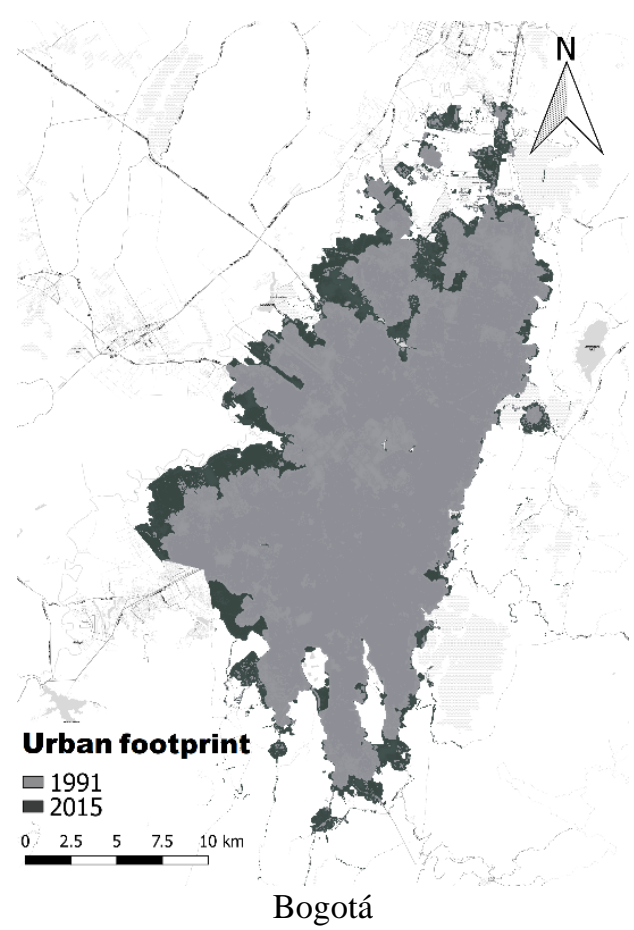

Figure 1. Urban footprint for Barranquilla and Bogotá

Both cities reflect patterns of spatial and social segregation. To understand accessibility and social patterns in the cities, it is necessary to identify the spatial and social distribution of the population. For the analysis, we divided both cities into zones with similar socioeconomic characteristics but also considering the presence of primary roads, natural barriers, and Land-Uses. These zones are known in Bogotá as UPZ (Urban Planning Zones) while in Barranquilla they are known as ZATs (Transport Analysis Zones). In total, because of data availability, we divided Bogotá in 112 UPZ and Barranquilla in 275 ZATs. Figure 2. Population density and income distribution for Bogotá and Barranquilla

shows population density and average income distributions in both cities, considering that we formed income groups according to their SES.

In $2012,44 \%$ of their zones belong to low-income groups, while $42 \%$ and $14 \%$ to mediumincome and high-income inhabitants respectively. About $89 \%$ of the inhabitants in Soledad, classify as low-income people, while $11 \%$ remaining belongs to SES 3. In Barranquilla, the southern zones have the highest population densities, which correspond where low-income 
1 people live (Figure 3). Such spatial and social segregation has been compounded by other 2 structural deficits and vulnerabilities. Most neighbourhoods in Soledad and southern zones 3 in Barranquilla are informally developed, leading to limited access to infrastructure, public 4 spaces and coverage of public transport, as well as higher environmental risks such as 5 flooding (Dávila et al., 2017). Such phenomenon has made residents in those areas more 6 vulnerable, with a significant number of people classified below the poverty line (Mertins, 7 2007).

8 In Bogotá, a similar phenomenon occurs regarding population and income distribution. 9 The lowest-income zones have the highest population density, while the opposite happens 10 to the wealthiest zones that have lower population density. Low-income inhabitants live in 11 the urban periphery (Figure 2d), in highly dense neighbourhoods (Figure 2c) also marked 12 by informal development, concentration of poverty and disadvantage, and a large influx of 13 forcedly displaced populations (Guzman, Oviedo, \& Bocarejo, 2016; Skinner, 2004).

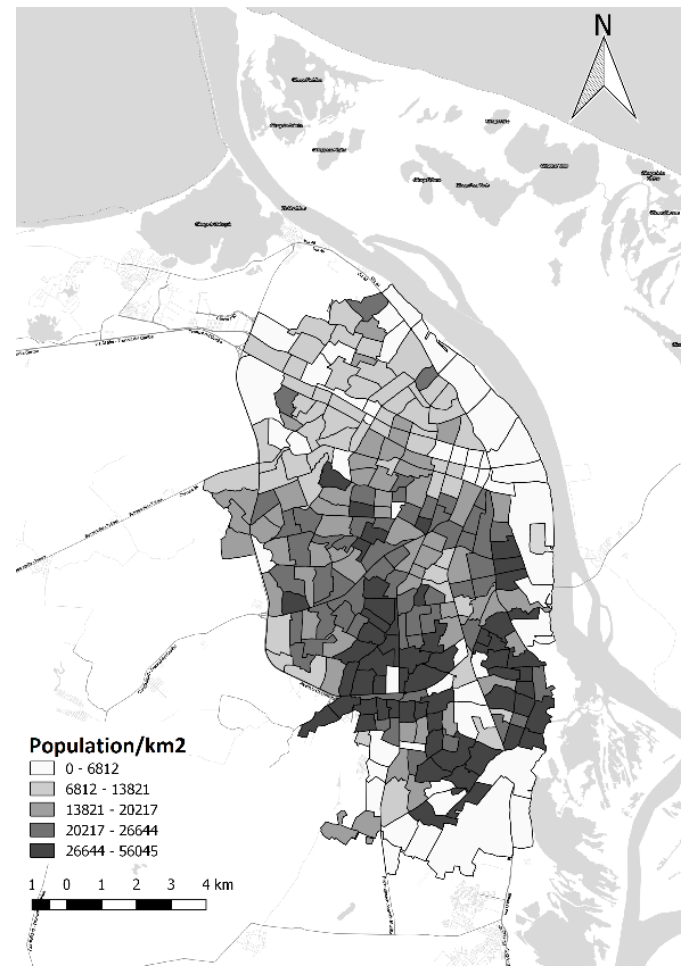

a) Population density in Barranquilla

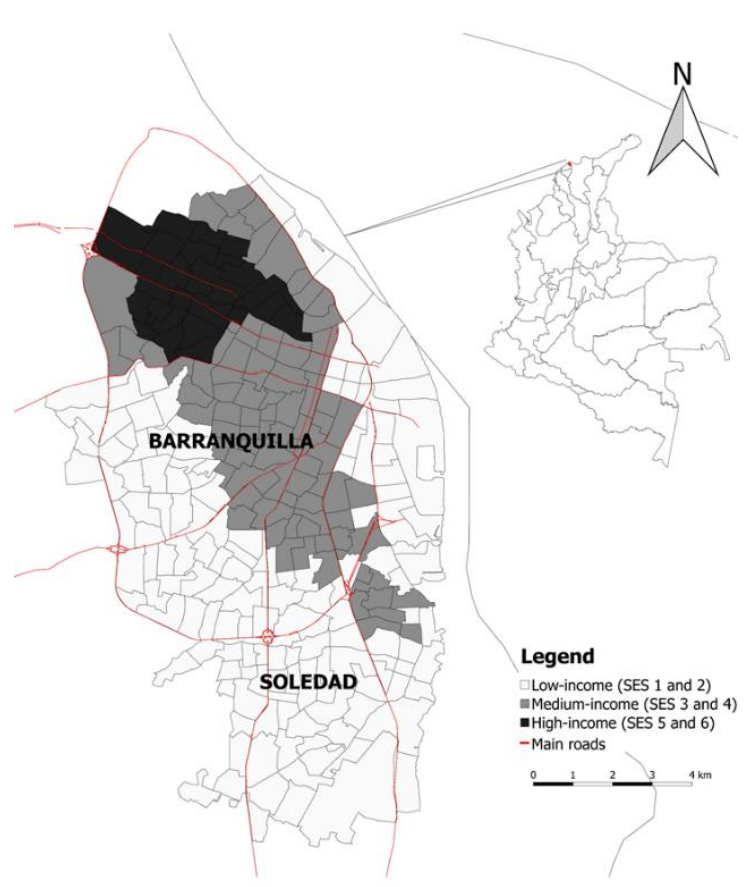

b) Income distribution in Barranquilla 


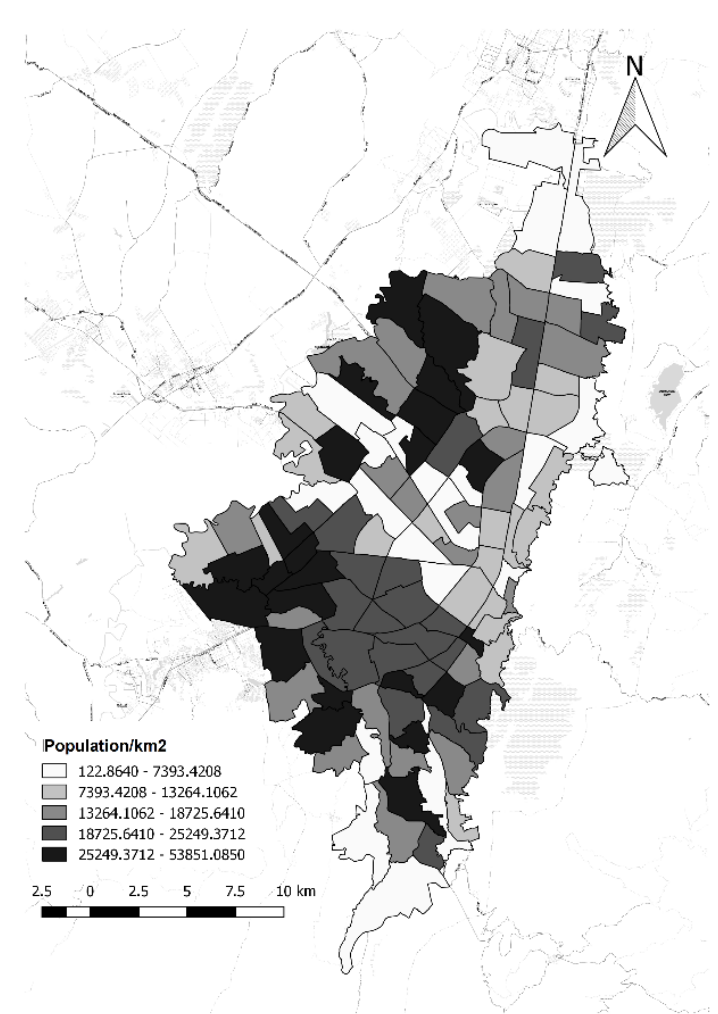

c) Population density in Bogotá

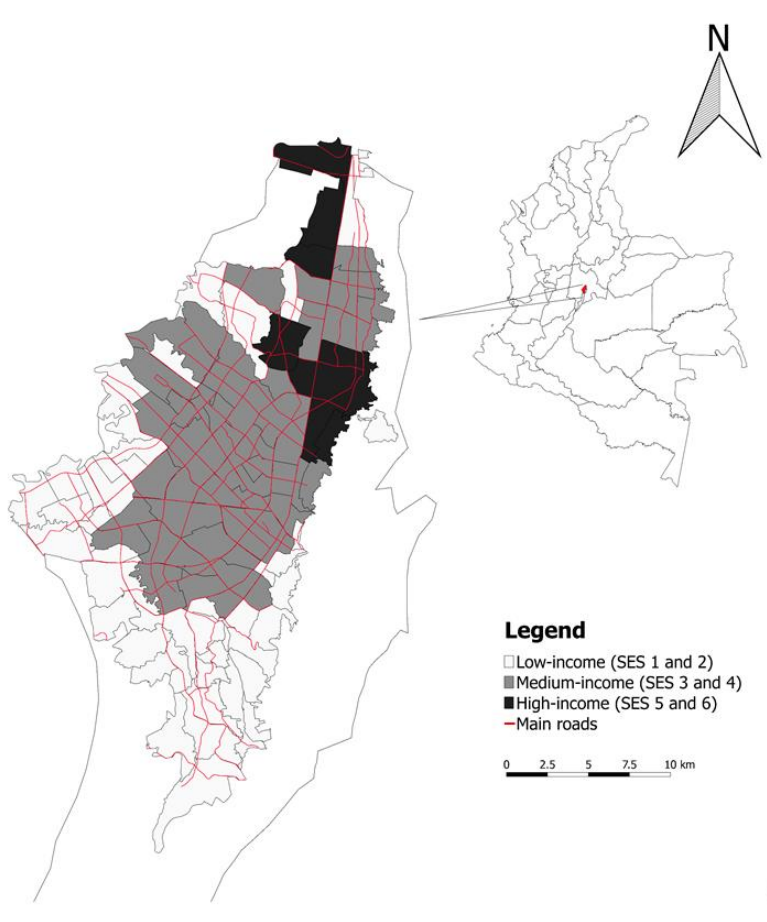

d) Income distribution in Bogotá

Figure 2. Population density and income distribution for Bogotá and Barranquilla

2

Both cities also reflect similar patterns of vehicle ownership (Figure 3). The wealthiest zones have higher vehicle ownership rates per household than lower-income zones. In Barranquilla, the range of vehicle ownership per household in the northern zones oscillates between 0.58 and 2.20. In Bogotá, the greatest vehicle possession concentrates towards the northern part of the city, with an ownership rate between 0.86 and 2.8 vehicles per household. The higher vehicle ownership rates in Bogotá compared to Barranquilla can be attributed to a combination of higher income and the effects of the city's license-plate-based circulation restriction policy implemented in the capital. Some authors report that this policy incremented the number of cars registered in the city because people who can afford to buy another motorised vehicle will do it to avoid the measure (Guzman et al., 2020; Ramos et al., 2017). Vehicle ownership decreases markedly towards the most deprived areas of the cities, located towards the south and the periphery in both cases (Figure 3). 


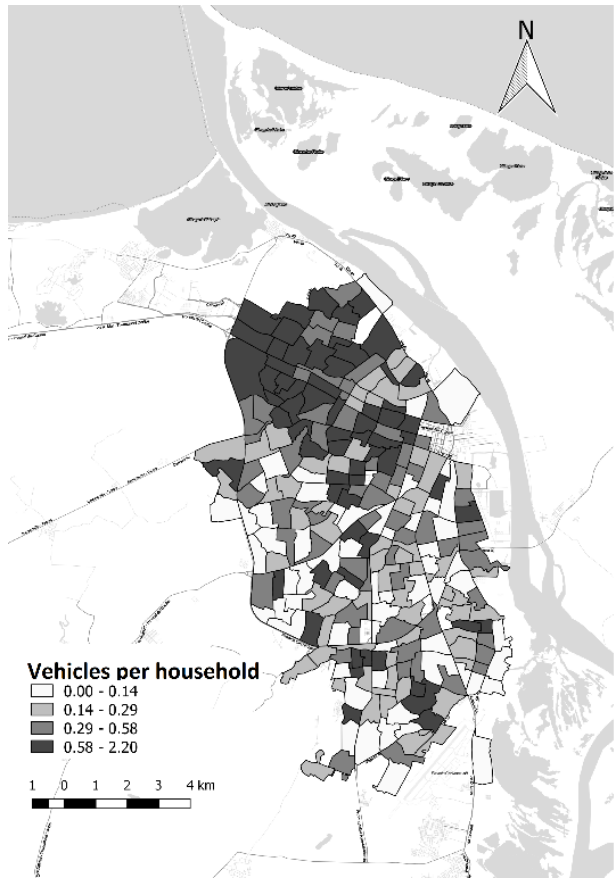

Barranquilla

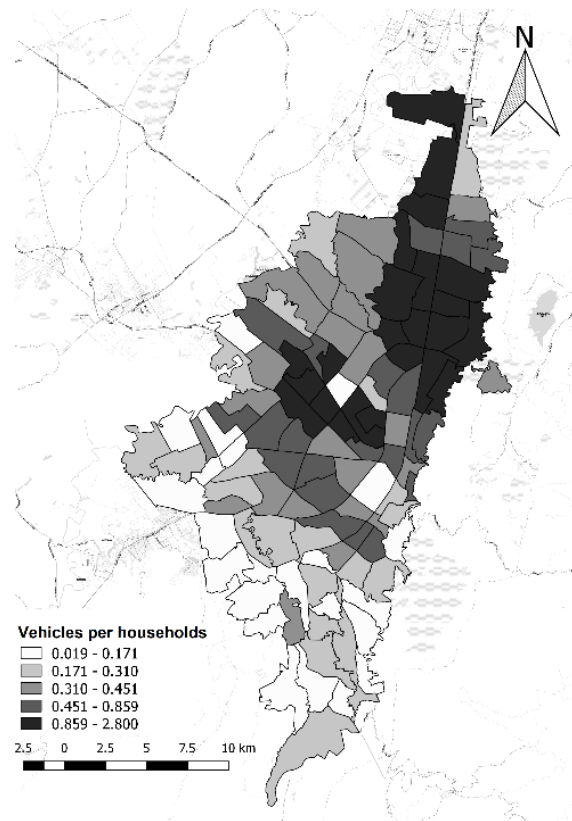

Bogotá

Figure 3. Vehicles per household

2 In understanding urban trajectories, the spatial distribution of opportunities can provide for 3 a proxy of the historical consolidation of the social and functional patterns of the city $\{\mathrm{s}$ 4 planning and development. Land-use is as relevant for accessibility, being a key driver in the 5 ability of social groups and individuals to reach opportunities. In this paper, we considered 6 work and study opportunities, included formal and informal workplaces. Figures $4 \mathrm{a}$ and $4 \mathrm{~b}$ 7 show the concentration of opportunities in Barranquilla and Bogotá represented as the 8 number of work and study places divided by the area of the zone. The map also includes the road network and public transport densities to support the analysis. 


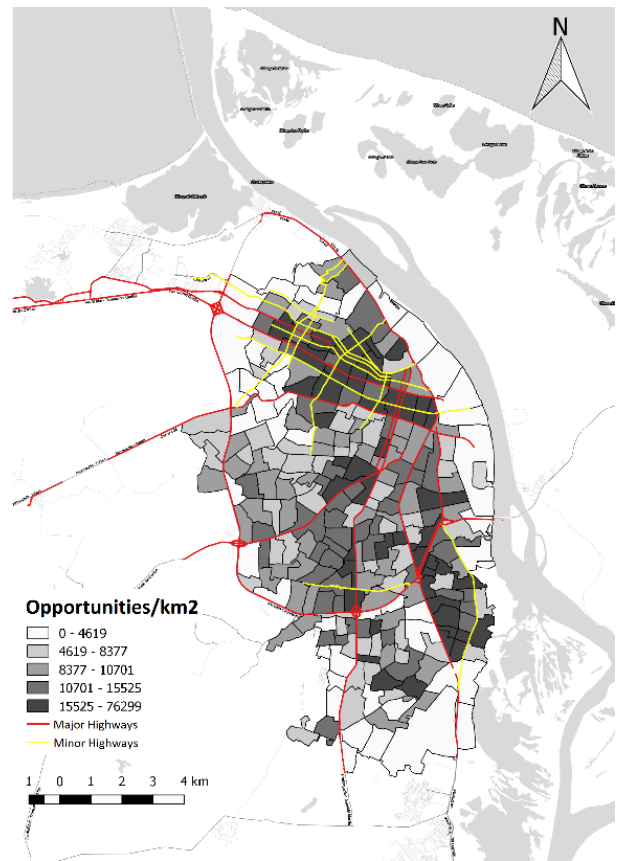

a) Density of opportunities in Barranquilla

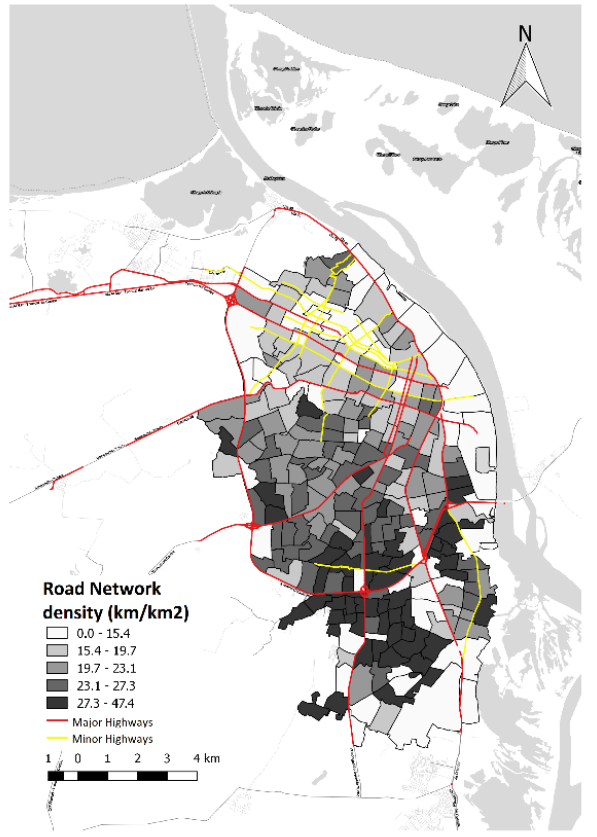

c) Road network density in Barranquilla

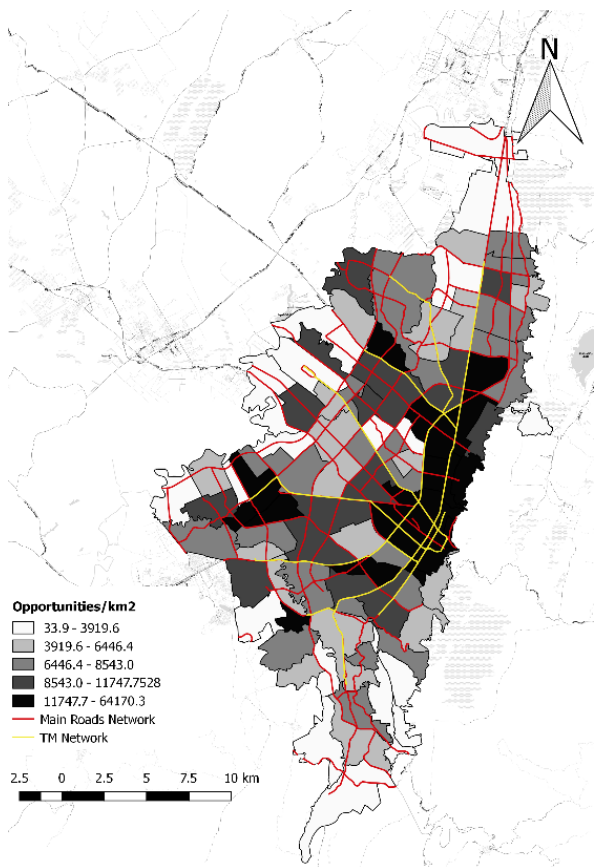

b) Density of opportunities in Bogotá

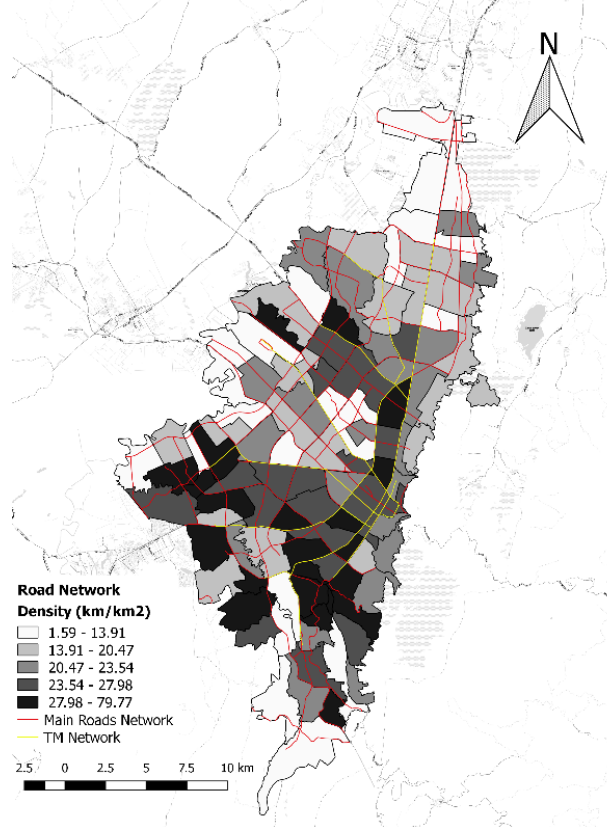

d) Road network density in Bogotá 


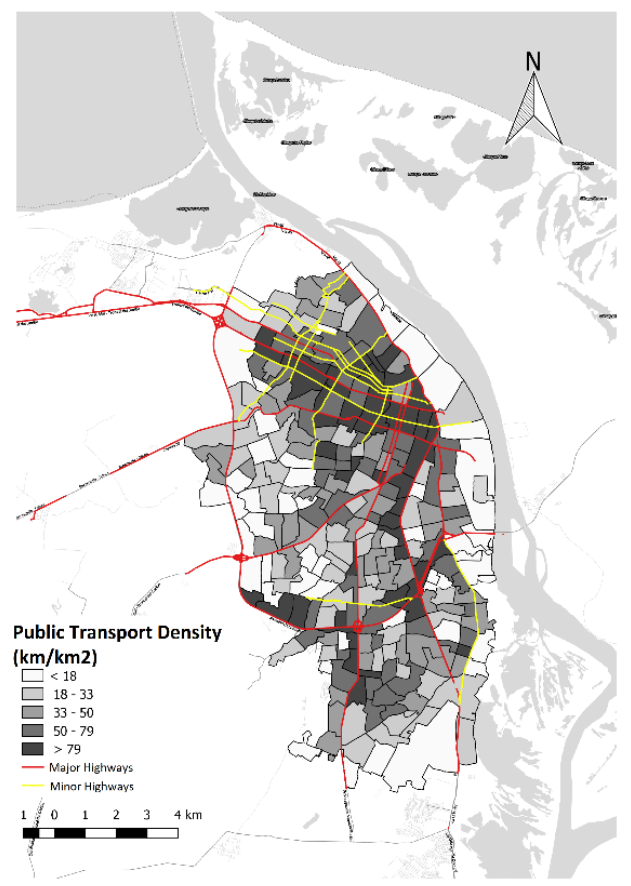

e) Public transport density in Barranquilla

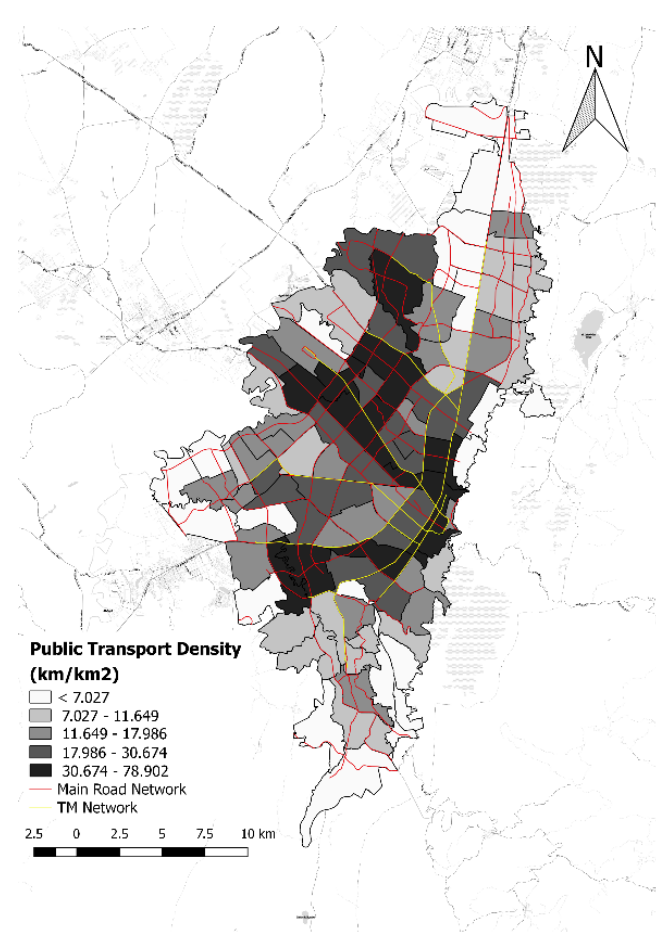

f) Public transport density in Bogotá

Figure 4. Density of opportunities, roads and public transport for Barranquilla and Bogotá

The spatial distribution of opportunities and transport supply show visible similarities in both contexts. Opportunities are concentrated mostly in the main centralities of the cities which coincide with downtown and northern areas (Figures $4 \mathrm{a}$ and $4 \mathrm{~b}$ ), just in the vicinity of main roads and BRT networks (Figure 4f). It is important to highlight that public transport systems in both cities comprise mass public transport corridors (i.e. BRT systems) and regular buses. The highest public transport densities are in zones with more opportunities which have access to the trunk corridors but lower in peripherical zones (Figures $4 \mathrm{e}$ and $4 \mathrm{f}$ ). The above suggests that people who live in the lowest-income zones are the ones who experience the lowest public transport availability. In southern zones, public transport density is lower than in the northern zones, and it is related to the less favourable condition of the infrastructure.

Regarding road density, the southern zones, which are where the lowest-income people live, have the highest number of roads per area in both cities (Figures $4 \mathrm{c}$ and $4 \mathrm{~d}$ ). Nevertheless, these densities are the result of the absence of a robust urbanistic growth plan and urbanisation processes, which translates into denser roads with low capacity, blocks of smaller size, and poor infrastructure conditions in lowest-income zones. Conversely, in the wealthiest zones of the cities, the urbanistic growth has been more ordered, with blocks and households with more area.

Although public transport policies have played an important role in the urban trajectories of both cities, marked differences in urban transport policies both in the years leading to the time of analysis (Rodriguez et al., 2017) in each city suggest their pathways of urban and transport development have diverged. As shown in Table 3, Bogotá's urban transport policies since 1998 have increasingly challenged patterns of urban mobility focused on the private 
vehicle, giving priority to investments and operational reforms focusing on the improvement of public transport and restrictions to the private vehicle. In Barranquilla, however, most policies have been focused on regulating the use of private transport. Although Barranquilla's BRT was implemented in 2010, only until 2015 a unified transport authority for the Barranquilla Metropolitan region was created. Therefore, public transport measures began formally until then, which contrasts with Bogotá, where policies favouring this transport mode are older. The above could be one of the primary causes for more considerable city sprawl compared to Bogotá in a similar period. Similarities and differences in spatial and economic dimensions of accessibility reflect the challenging conditions for developing inclusive transport systems in these cities. Adopting an accessibility framework, policies in Table 3 also highlight the specific component of accessibility affected by the most prominent policies in each city, suggesting a much larger focus on the transport component of accessibility.

14

Table 3. Urban transport policies in Bogotá and Barranquilla

\begin{tabular}{|c|c|c|c|}
\hline City & Year & Policy & Accessibility component \\
\hline \multirow{12}{*}{ Bogotá } & 1998 & $\begin{array}{l}\text { Vehicle restrictions based on license plate } \\
\text { numbers }(4 \mathrm{~h} / \text { day })\end{array}$ & Transport \\
\hline & 2000 & Land-Use Master Plan & Land-Use \\
\hline & 2001 & Implementation of BRT phase $1(42.3 \mathrm{~km})$ & Transport \\
\hline & 2009 & Vehicle restrictions extension to $14 \mathrm{~h} /$ day & Transport/Time \\
\hline & 2004 & Land-Use Master Plan modifications & Land-Use \\
\hline & $2003 / 2005$ & Implementation of BRT phase $2(48.9 \mathrm{~km})$ & Transport \\
\hline & $2012 / 2013$ & Implementation of BRT phase $3(21.7 \mathrm{~km})$ & Transport \\
\hline & 2012 & Vehicle restrictions reduction to $7 \mathrm{~h} /$ day & Transport \\
\hline & 2012 & $\begin{array}{c}\text { Implementation (gradual) of the new } \\
\text { integrated public transport system (regular } \\
\text { buses) }\end{array}$ & Transport \\
\hline & 2013 & Pro-poor public transport subsidy & Transport/individual \\
\hline & 2016 & Restructuring of BRT routes & Transport \\
\hline & 2018 & Cable car operations started & $\begin{array}{l}\text { Transport/individual/Land- } \\
\text { Use }\end{array}$ \\
\hline \multirow{6}{*}{ Barranquilla } & 2000 & Land-Use Master Plan & Land-use \\
\hline & 2007 & Land-Use Master Plan modifications & Land-use \\
\hline & 2010 & Implementation of BRT phase $1(13.3 \mathrm{~km})$ & Transport \\
\hline & 2010 & $\begin{array}{l}\text { Restrictions for mobility of motorcycles with } \\
\text { passengers in some zones of the city }\end{array}$ & Transport/individual \\
\hline & 2012 & Regulation of speed cameras & Transport \\
\hline & 2012 & Regulation of parking zones & Transport/Land-Use \\
\hline
\end{tabular}




\begin{tabular}{ccc}
\hline 2013 & $\begin{array}{c}\text { Land-Use master plan for the Barranquilla } \\
\text { Metropolitan region } \\
2014\end{array}$ & Land-use \\
\hline $2013-2015$ & $\begin{array}{c}\text { Vehicle restrictions based on license plate } \\
\text { numbers during road constructions in the } \\
\text { northern zones of the city }\end{array}$ & Transport/Land-Use \\
\hline 2015 & $\begin{array}{c}\text { New public transport authority for the } \\
\text { Barranquilla Metropolitan region } \\
\text { Creation of fare stabilization fund for public } \\
\text { transport operations }\end{array}$ & Transport/Land-Use \\
\hline 2016 & $\begin{array}{c}\text { Expected implementation of the new } \\
\text { integrated public transport system (regular } \\
\text { buses) }\end{array}$ & Transport \\
\hline 2020 & $\quad$
\end{tabular}

Policies in Barranquilla and Bogotá have arguably contributed to their observed social, economical and functional configuration, defining, respectively more public-transportoriented and car-oriented urban trajectories. After comparing the density of opportunities with the population density, we identified that zones with less population density are closer to zones with more opportunities, suggesting that both cities have similar trip patterns. Those zones correspond to the wealthiest ones, which suggest that low-income people experience more time travelling to work and study than higher-income inhabitants. Figure 5 presents average travel times for Barranquilla and Bogotá, suggesting marked spatial inequalities in transport access in both cities.

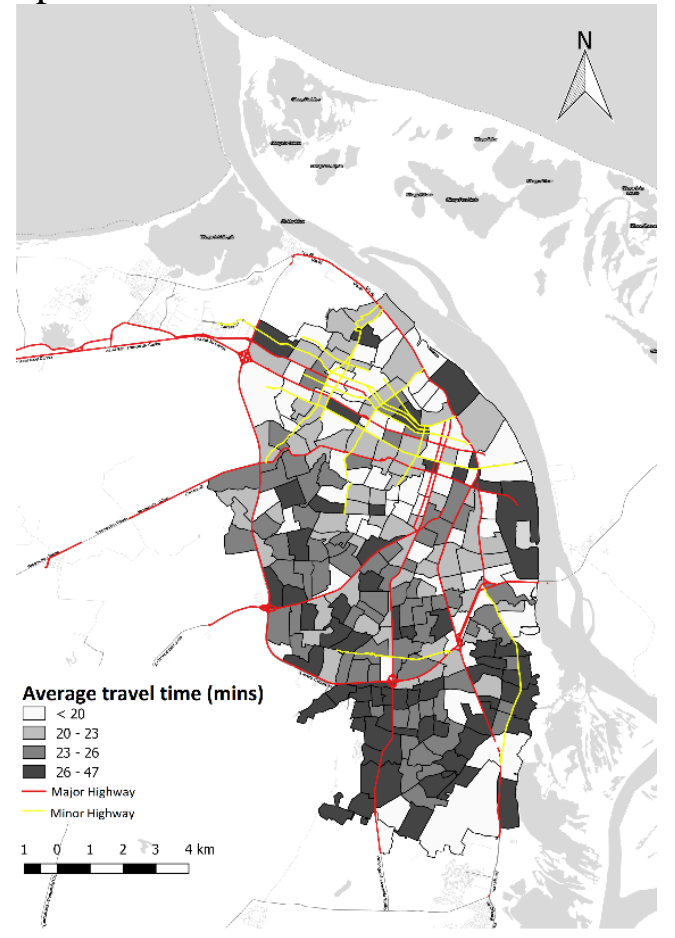

a) Barranquilla

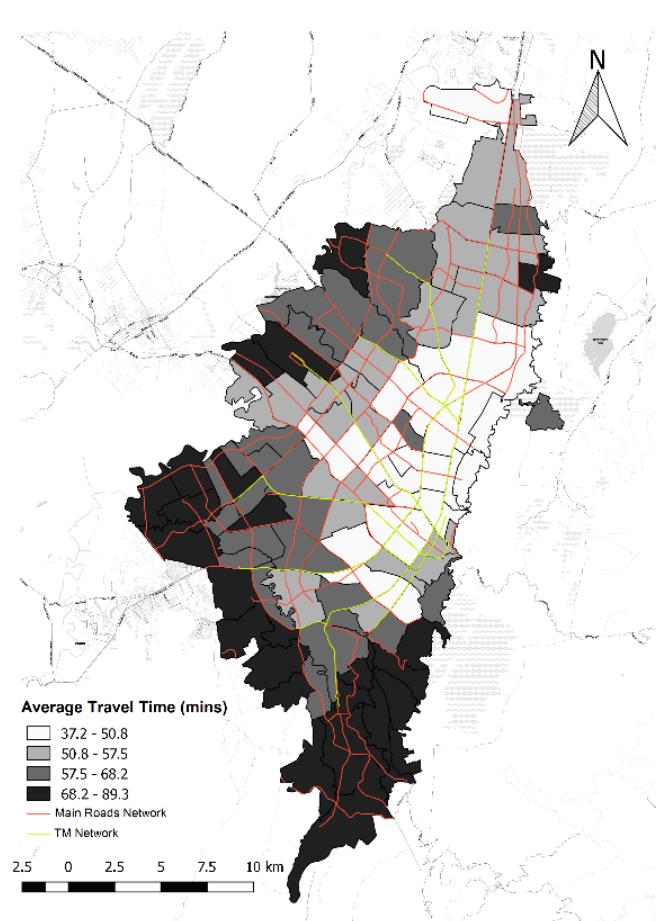

b) Bogotá

Figure 5. Average travel time

The lowest-income zones in Barranquilla have an average travel time of 24.2 minutes, while middle and high-income zones experience shorter travel times (i.e. 21.2 minutes). In Barranquilla, we did not find significant differences in travel time by car considering income 
groups. However, the average travel time of public transport users travelling from lowincome zones was 31.4 minutes, while from medium and high-income zones, travel times were 25.2 and 24.7, respectively. Therefore, low SES inhabitants last $27 \%$ more than the other groups to complete their work and study trips. In Bogotá, the lowest-income inhabitants experienced 49 minutes by car and 71 minutes by public transport, respectively. Meanwhile, people who live in medium-income zones experienced 42 minutes by car and 58 minutes by public transport. Finally, individuals who live in high-income zones experienced 41 minutes by car and 54 minutes by public transport. Those values show that people from the lowest SES who travel in public transport spend 32\% more time travelling than people who belong to the highest SES.

Although transportation plays a primary role in the morphological pattern of a city (Levy, 1999), we should recognized that the urban growth of Latin American and Global South cities are the product of quite complex processes that involves multiple dimensions. Social, physical, environmental, economic, cultural, and political dimensions also intervene in the cohesion and coherence of the city grow patterns (Bocarejo et al., 2016). Urban dynamics, such as suburbanisation, mobility patterns, governance issues, and the emergence of peripheral centralities, among others, have caused that some Global South cities to growth as fractured pieces rather than a unit.

In Colombia, for instance, national population growth, violence and economic crisis in the country during the nineties caused massive rural-urban migrations throughout the country, and the expansion of slums mainly in the periphery of its main cities (Aldana-Domínguez et al., 2018). Those nationwide problems along with governance weaknesses contributed to fast growing rates of unemployment, informal employment, and the urbanization of the peripheries in the city during those times (Aldana-Domínguez et al., 2018).

Then, it is important to acknowledge that the urban growth in Colombia in the last century has been mainly unplanned and informal (Andrade et al., 2013). Peri-urban areas in the cities are normally viewed as the home of the slum population. Maybe this is caused by the informality, which has been the main form of access to urban land for those poor and marginalized populations in Latin American countries (Abramo, 2012). These zones exhibit the fastest growing population rates and experience the most precarious living conditions in the city. Peri-urban irregular sprawl often represents poor housing and built environment conditions, violence, and several environmental hazards, including deforestation, poor sanitation, and pollution (da Gama Torres, 2011). Institutional dimensions related to property rights, land tenure legislation, income distribution, credit availability, and land market prices have influenced the proliferation of these peri-urban irregular settlements (Inostroza et al., 2013).

Furthermore, the usual process of gentrification, which happens where others with higher purchasing power displace the original population of some neighbourhoods, transforming the urban landscape (García-Ayllón, 2016) has been favoured for the increments of land values in central areas of the city. Then, Global South cities have to deal with people "forced" to move to areas far from the economic centres, generally in the outskirts of the cities. These areas are characterised by lack of access to shelter, infrastructure, services and serious environmental issues (Watson, 2009). The above pattern is supported by empirical evidence 
showing that the built-up densities in South America are falling in central areas and increasing at the periphery (Inostroza, 2017).

Bogotá and Barranquilla are therefore examples of the urban growth patterns in the Global South context. Even though Bogotá has shown a one-third increase in net built-up density during the last 20 years (Inostroza et al., 2013), which is different from other cities in the region, its population increased in a 10 time proportion during the last 50 years, while the urban footprint increased more than $20 \%$. At the expense of natural vegetation, the high population growth was accompanied by the construction of informal settlements in the surroundings of the city (Anselm et al., 2018). Barranquilla followed a similar pattern in terms of the settlement areas, which grew by approximately $50 \%$ in a 30 -year period (Schubert et al., 2018). Aldana et al. (2018) using a social-ecological perspective describes a similar growth pattern of a segregated city that we found in our analysis. They describe Barranquilla as a city divided in a modern, clean and organized area in the north which contrasts with older neighbourhoods that look dirty and chaotic in the south. They also note that most of the recreational options and public investments are mostly concentrated in the northern zone. Thus, not all people benefit from them.

The above analysis highlights the importance of developing combined efforts using a multidisciplinary perspective to understand socio-spatial segregation patterns, which are similar in both cities and are reflected by accessibility inequalities, housing types, the quality of constructions, and the infrastructure endowments (Mertins, 2007).

\section{Results and discussion}

We examine the accessibility and affordability consequences of the urban trajectories followed by Barranquilla and Bogotá, focusing on the distribution of winners and losers from different income groups. These two metrics and their comparison across zones enable an analysis of transport inequalities within a broader context of urban and transport development focused on specific forms of transport and socioeconomic profiles.

Figure 6 shows the distribution of accessibility per capita for private transport in Barranquilla and Bogotá. In general, both cities have a similar distribution pattern of accessibility per capita, suggesting considerable horizontal inequalities. The accessibility measure is higher for the wealthiest zones of the city while decreases for the lower-income areas. In Barranquilla, the highest accessibility values are in the northern zones and the downtown of the city (Figure 6a), which is associated with a higher concentration of opportunities and with higher car-ownership rates. Zones with the lowest accessibility per capita in the city are in zones where the poorest residents live. In Bogotá, accessibility per capita is higher in the downtown area than in other zones. The spatial distribution of the accessibility denotes that average access to work and study opportunities favour high-income groups. Results suggest that high and middle-income groups of the population can access $5 \%$ and $23 \%$ more of the work and study opportunities than the number of opportunities that an average inhabitant of Bogotá can reach by private transport. 


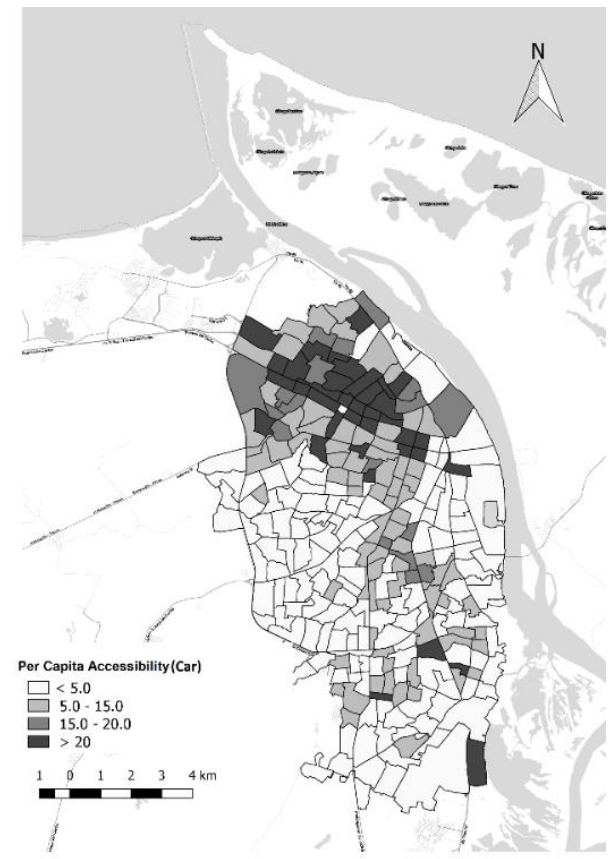

Barranquilla

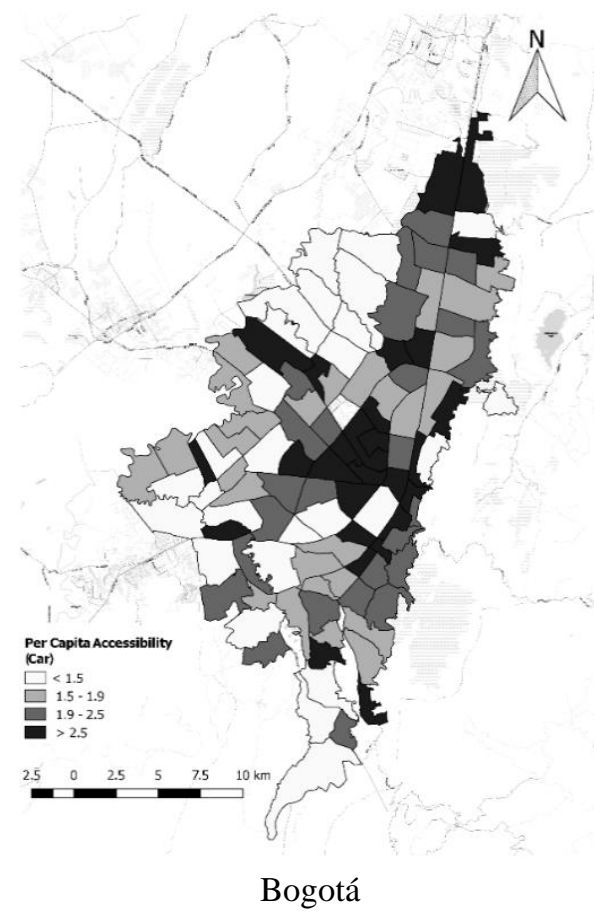

Figure 6. Accessibility per capita for private transport in Barranquilla and Bogotá

The distribution of public transport accessibility in both cities also unveils a marked pattern of horizontal inequality in which the peripheral areas of the city are less served than those areas closer to the main centralities (Figure 7). In Barranquilla, public transport accessibility is higher in most of the northern zones and the downtown area, suggesting planning and urban development patterns that have reinforced the connectivity in these areas while bypassing less attractive and poorer zones of the city (Oviedo Hernandez \& Dávila, 2016). Public transport accessibility is lower in the lowest-income and most populated zones. The above contradicts local, national and global rhetoric about equality and inclusion as target objectives of urban planning (Dávila et al., 2017; Jaramillo et al., 2012; UNDP, 2016). Low-income inhabitants should have higher public transport supply as most of them in these cities do not have access to private transport alternatives and are captive users of public transport to travel long distances. However, this does not happen in the Barranquilla region, despite clear efforts for investing more in public transport across the city, as shown in Table 2.

We divided the analysis of public transport accessibility for Bogotá into two categories: regular buses (CPT) and trunk corridors of the mass transit system (TM). Figures $7 \mathrm{~b}$ and 7c present the distribution of the accessibility considering both public transport components. The spatial pattern of accessibility values considering only CPT is similar to Barranquilla's. The lowest accessibility values per capita are in the periphery and the densest zones in the city. Furthermore, accessibility is higher near the main centrality. Even though the distribution of accessibility considering TM also reveals the highest level of accessibility per capita in the centrality, it is interesting to note that the mass transit system provides high accessibility values for inhabitants located in the periphery near the terminals of their trunk 
services. As expected, the CPT system seems to offer access to a higher number of areas in the city than TM because of its greater geographical coverage.

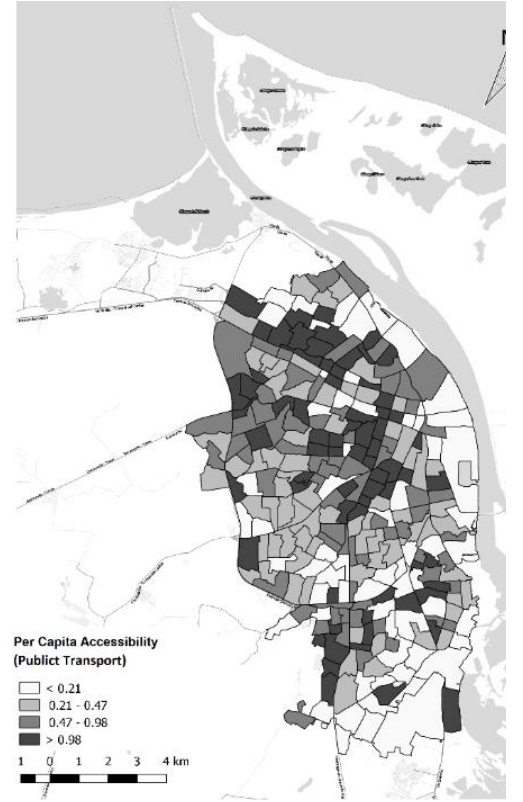

a) Barranquilla

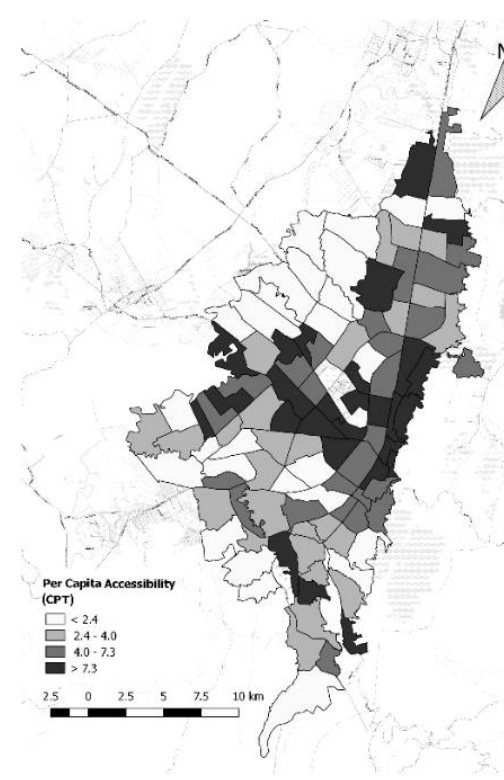

b) Regular buses (CPT) Bogotá

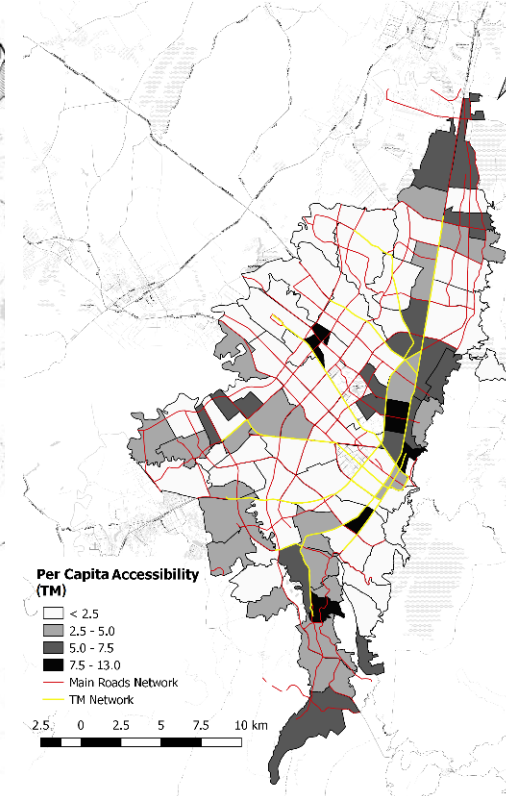

c) Mass transit Bogotá

Figure 7. Accessibility per capita for public transport in Barranquilla and Bogotá

Table 4 shows a comparison of average per capita accessibility values for the different income groups and transport modes. First, on average, the magnitude of the accessibility per capita by car in Barranquilla is 4.48 times greater than Bogotá. The above result could be related to the congestion levels experienced in Bogotá and the travel demand management policies implemented, which makes the use of private transport less attractive than in Barranquilla. Considering both private and public transport accessibilities, suggest that Barranquilla is a more car-oriented city than Bogotá. Indeed, the average public transport accessibility values support the above idea. Values in Bogotá are higher than the one for public transport in Barranquilla. The magnitude of the accessibility per capita by public transport in Barranquilla is one fourth compared to the accessibility per capita value by CPT and half concerning TM in Bogotá.

Table 4. Average per capita accessibility

\begin{tabular}{lccccc}
\hline \multirow{2}{*}{ Income group } & \multicolumn{3}{c}{ Barranquilla } & \multicolumn{3}{c}{ Bogotá } \\
\cline { 2 - 6 } & Car & Public transport & Car & CPT & TM \\
\hline Low-income & 6.26 & 1.15 & 1.98 & 4.28 & 3.07 \\
Medium-income & 14.00 & 1.80 & 2.36 & 7.16 & 3.05 \\
High-income & 26.48 & 1.34 & 2.76 & 8.71 & 4.01 \\
City Average & 10.06 & 1.52 & 2.24 & 6.12 & 3.14 \\
\hline
\end{tabular}

Average per capita accessibility by car and public transport considering income groups also show vertical inequalities in both cities. Accessibility per capita values by car increase with the income (i.e. the higher the income, the higher the potential accessibility per capita 
by car). The pattern is similar for accessibility per capita by CPT in Bogotá, while is not necessarily valid for public transport and TM in Barranquilla and Bogotá, respectively. In Barranquilla, the highest average accessibility per capita by public transport is in the medium-income group while in Bogotá, it seems that there is no difference in accessibilities per capita between low and medium-income people using TM. Another interesting result can be obtained when comparing CTP and TM per capita accessibilities. On average, CTP per capita accessibility is 1.95 times higher than TM per capita accessibility. In both cases, lowincome households have average per capita accessibility values lower than the city average.

We estimated inequality indices to visibilise the differences in potential pedestrian accessibility for inhabitants in both cities and to provide evidence on distributional effects of accessibility. We estimated Gini coefficients throughout the cities using Lorez curves considering the population in each zone following a similar approach to the one suggested by Guzman et al. (2017). The Gini index ranges from 0 to 1, where zero corresponds to perfect equality (i.e. everyone experiences the same accessibility) and one refers to perfect inequality (i.e. one individual has all the accessibility, while the rest none). These indices were lower for private transport than for public transport in both cities, confirming the existence of considerable differences in accessibilities across the study area, regardless of the transport mode. Also, the GINI indices suggest that the use of the car in Barranquilla is more attractive than in Bogotá. In Bogotá, the differences between the GINI indices by car and public transport are shorter than in Barranquilla. Figure 8 shows the Lorenz curves, where we compare the potential accessibility measure with the population by zone. The result suggests that $50 \%$ of the inhabitants of Barranquilla and Bogotá shared approximately $30 \%$ of the potential accessibility.

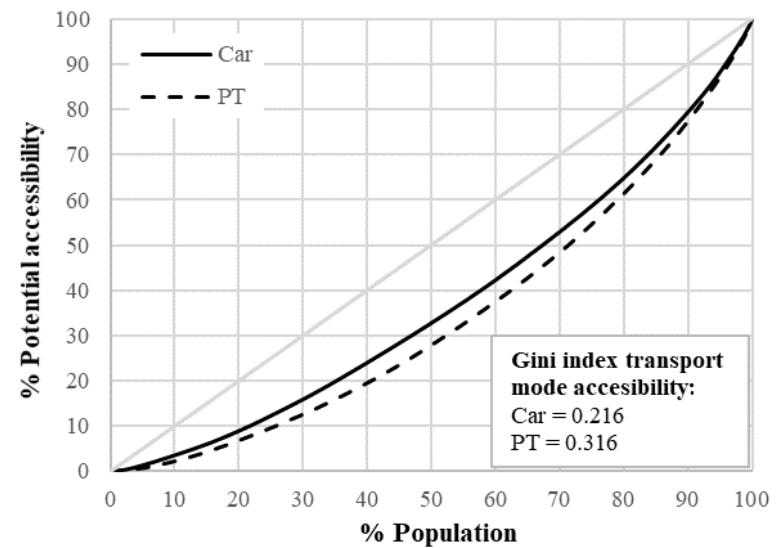

Barranquilla

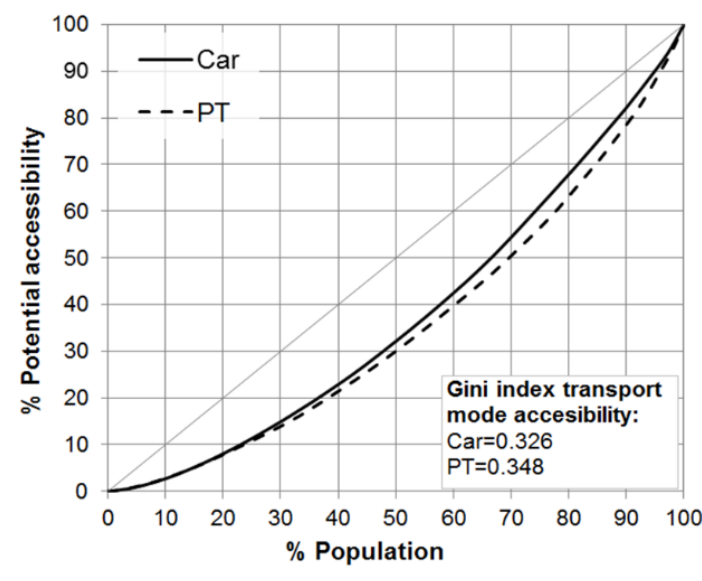

Bogotá

Figure 8. Lorenz curves of population and Gini indices for car and public transport (PT)

The spatial distribution of affordability indices and the differences among income groups in Barranquilla and Bogotá also reflects considerable horizontal and vertical inequalities (Figure 9). The lowest-income groups exhibit higher affordability indices which mean that they invest a higher proportion of income in transport costs. On average, Bogotá's citizens invest approximately $11 \%$ of their income, while individuals living in Barranquilla invest about $8 \%$ of their income on transport costs. For all income groups, the affordability indices 
in Barranquilla are lower than those in Bogotá, indicating that people in the capital spend more of their incomes on their mandatory trips.

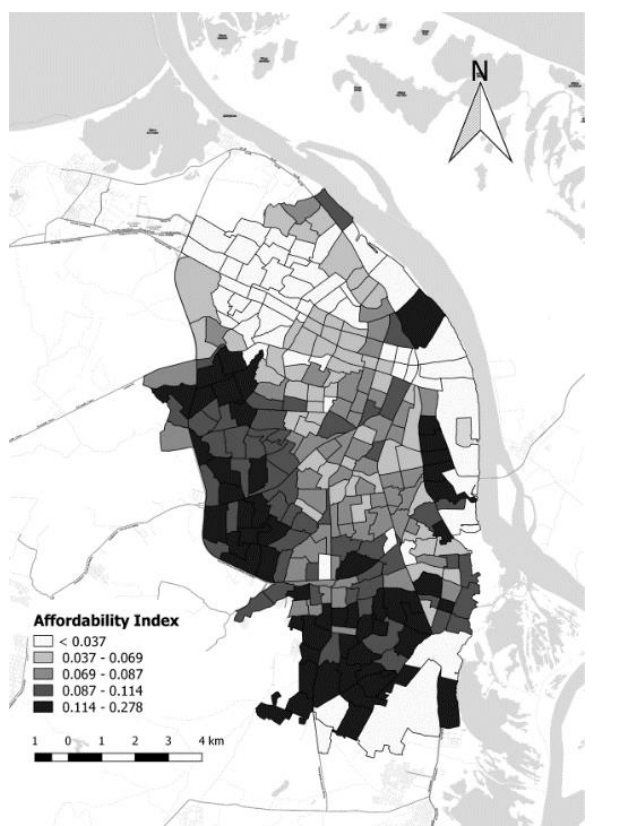

\begin{tabular}{cc}
\hline Income group & Barranquilla \\
\hline Low-income & 0.098 \\
Medium-income & 0.061 \\
High-income & 0.019 \\
\hline City average & 0.077 \\
\hline
\end{tabular}

\begin{tabular}{cc}
\hline Income group & Bogotá \\
\hline Low-income & 0.162 \\
Medium-income & 0.093 \\
High-income & 0.024 \\
\hline City average & 0.115
\end{tabular}

Figure 9. Affordability index

\section{Conclusions}

Our paper compared vertical and horizontal equality in accessibility in Barranquilla and Bogotá as a way to reflect on the distributional consequences of different urban trajectories from a transport planning perspective. Despite differences in population, urban form, and extension, the spatial distribution of both potential accessibility and affordability measures suggest similar patterns of inequalities across the two territories of analysis. This finding suggests that despite recent divergence in the focus of urban and transport planning policies and decisions that may influence different components of accessibility, the long-term effects of segregating and unequal urban trajectories have led to similar levels of inequalities in both cities, at least in aggregate levels. From a macro perspective, the wealthiest areas benefit from better car accessibility per capita, public transport supply, and concentrate on the greatest number of work and study opportunities. By contrast, the most prominent affordability problems occur in the lowest-income zones in both cities, with low-income communities facing more significant barriers for accessing opportunities than their higherincome counterparts. Furthermore, average travel times are higher for people who live in low-income zones in both cities. In Bogotá, this group spends about 89 minutes travelling to their work or study places, which represents almost double compared to the value for the similar group in Barranquilla. This suggests that when considering the city as a whole, years 
of self-reinforcing cycles of segregation and unequal access to transport and land-use have locked the two cities in trajectories that put the poor at a disadvantage compared to higherincome groups.

However, when unpacking further the findings, we found that despite similar patterns in terms of spatial distribution, potential accessibility per capita values between Barranquilla and Bogotá are quite different. First, when we talk about car accessibility, Barranquilla reflects higher values than Bogotá. In both cities, low-income inhabitants experience lower potential accessibility values than the city's averages, in line with the previous conclusion. There is a large gap among income groups regarding car accessibility. In Barranquilla, highincome zones experience an average car accessibility value 4.2 times greater than people from low-income zones. In Bogotá, the gap is lower than in Barranquilla, but it stills being a significant difference between high-income zones and low-income zones (i.e. 1.93 times greater in high-income zones). This starts introducing noise to aggregate findings, suggesting that some of the restrictive policies applied in Bogotá for the private vehicle, may have reduced the gap between the car-owner rich and its poorer counterpart. Second, Bogotá's average values of public transport accessibility are higher than those for the Barranquilla region. Average accessibility measures for the rich and the poor in the public transport system in Barranquilla and the mass transport system in Bogotá are not as different as those obtained for private transport. The accessibility gap is more notorious for those travelling by regular buses in Bogotá, showing that high-income people can access about twice the number of job and study opportunities compared to the lowest-income inhabitants. This finding suggests that policies supporting public-transport-oriented urban trajectories still have a largely unequal effect in their spatial and social distribution, questioning the ability of policies targeting expansion of public transport systems under mainstream criteria of prioritisation such as attractiveness and demand to redress long-term social and spatial inequalities. Third, we observed that, on average, people in Bogotá spend 1.49 times more money travelling for mandatory purposes than individuals in Barranquilla. The affordability gap between high and low-income inhabitants in both cities is striking because low-income people spend around 5 and 7 times more percentage of their monthly income than people from high-income areas.

Despite their similarities, our analysis reveals the effects of long-term decision-making in the number of opportunities which can be reached by different transport modes. Accessibility per capita in public transport is higher in Bogotá than in Barranquilla, and vice versa in private vehicles. These results are consistent with nearly a decade of implementation of different urban transport policies in both cities, which in Bogotá have been more publictransport-oriented than in Barranquilla. Findings also suggest that although such policies can contribute to redefining urban trajectories, their effects in terms of accessibility and equality in the short and medium-term is unlikely to manifest. Similarities and differences in spatial and economic dimensions of accessibility serve as a mirror against which we assess transport's role in urban equality in similar global south cities. Our findings suggest that this type of analysis can add a necessary dimension to the analysis of long-term urban development patterns beyond traditional transport or land-focused approaches.

In line with the focus of the special issue in which this paper is framed, our findings also point at potential policy avenues to improve equity in Barranquilla and Bogotá. Targeted policies that have been tested in the past in the Bogotá context such as pro-poor public 
transport subsidies have a significant potential to reduce the accessibility gaps found in the two cities (Guzman \& Oviedo, 2018). While these can operate as the delivery mechanism to reduce inequalities in accessibility among rich and poor, they need to build on the recognition of a development trajectory that has benefited disproportionately private vehicle users, particularly in Barranquilla. Marginal increases in the costs associated to the use of the private car can contribute to fund schemes of public transport subsidies Schemes such as congestion fares and other explicit charges to the use of the car can go a long way in redistributing accessibility and inducing changes in travel behaviour in the two cities. Moreover, efforts for strengthening public transport reflected by recent reforms (GómezLobo, 2020) can be strengthened by a more explicit engagement of forms of unrouted public transport currently providing access to the most vulnerable population under conditions of informality and lack of integration. Our findings support the need for further integration of different forms of public transport suggested by previous research (Rodriguez et al., 2017), incorporating other forms of meso and micro accessibility in the available set of mobility alternatives for different population groups. This will require partnerships and coproduction that can build on evidence such as the presented in this paper to find common ground for collective action.

The paper also points at the need for more interdisciplinary research exploring different urban trajectories in a context of sustainable development. Despite our limited policy analysis, its combination with a snapshot analysis of accessibility suggests links between decisions in the short and long term and distributional effects of transport. Such type of analysis has the potential to be expanded in this and similar contexts, exploring additional cities that show both similar and more significantly different urban trajectories, testing further the apparent relationships discussed as part of our analysis. Moreover, there is a need to explore additional modes of transport and to examine the differences in accessibility at the meso and microscale.

A limitation of the current study lies in only considering urban trajectories related to transport planning decisions to explain urban growth. However, as explained in the text, this is a more complex process. Therefore, the importance of land in urban development (Garza \& Lizieri, 2019; Steel et al., 2017), urban governance (Inostroza, 2017), environmental policies (Schubert et al., 2018), and socio-ecological perspectives (Aldana-Domínguez et al., 2018) should also be considered in further studies.

Further studies should also consider the effects of informal transport on access inequalities to opportunities due to different urban trajectories produced by several urban and transport planning policies. In some cities of the Global South, despite the deficiencies in terms of safety and security, informal transport attractiveness regarding flexibility and affordability cause a high use of these transport modes, especially on peripheral and low-income areas, which experience a lack of adequate formal transport services.

Also, other topics that should be explored in further studies are social housing and gentrification because of the land value increments produced by urban and transport projects. Social housing policies in Global South cities are quite crucial for those inhabitants who are forced to move from urban areas to the periphery or those who cannot afford to live in some places located near essential opportunities. In the same vein, access equality implications 
caused by gentrification processes after the implementation of some urban transport projects are not well documented in the literature.

Finally, other measures to assess inequalities and affordability such as the Palma ratio, the Pietra ratio, the Schutz coefficient, or the Theil index should be used in further studies because they can lead to different conclusions.

\section{References}

Abramo, P. (2012). La ciudad com-fusa: Mercado y producción de la estructura urbana en las grandes metrópolis latinoamericanas. Eure, 38(114), 35-69. https://doi.org/10.4067/S0250-71612012000200002

Aldana-Domínguez, J., Montes, C., \& González, J. (2018). Understanding the Past to Envision a Sustainable Future: A Social-Ecological History of the Barranquilla Metropolitan Area (Colombia). Sustainability, 10(7), 2247. https://doi.org/10.3390/su10072247

Andrade, G. I., Remolina, F., \& Wiesner, D. (2013). Assembling the pieces: A framework for the integration of multi-functional ecological main structure in the emerging urban region of Bogotá, Colombia. Urban Ecosystems, 16(4), 723-739. https://doi.org/10.1007/s11252-013-0292-5

Anselm, N., Brokamp, G., \& Schütt, B. (2018). Assessment of Land Cover Change in PeriUrban High Andean Environments South of Bogotá, Colombia. Land, 7(2), 75. https://doi.org/10.3390/land7020075

Banister, D., \& Hickman, R. (2013). Transport futures: Thinking the unthinkable. Transport Policy, 29, 283-293. https://doi.org/10.1016/j.tranpol.2012.07.005

Bárcena, A., \& Byanyima, W. (2016). Latin America is the world's most unequal region. Here's how to fix it $\mid$ Article | Economic Commission for Latin America and the Caribbean. Economic Commission for Latin America and the Caribbean.

Benevenuto, R., \& Caulfield, B. (2019). Poverty and transport in the global south: An overview. Transport Policy, 79, 115-124. https://doi.org/10.1016/j.tranpol.2019.04.018

Bertolini, L., le Clercq, F., \& Kapoen, L. (2005). Sustainable accessibility: a conceptual framework to integrate transport and land use plan-making. Two test-applications in the Netherlands and a reflection on the way forward. Transport Policy, 12(3), 207220. https://doi.org/10.1016/j.tranpol.2005.01.006

Bocarejo, J P, \& Oviedo, D. (2012). Transport accessibility and social inequities: a tool for identification of mobility needs and evaluation of transport investments. Journal of Transport Geography, 24, 142-154. https://doi.org/10.1016/j.jtrangeo.2011.12.004

Bocarejo, Juan Pablo, Portilla, I., \& Meléndez, D. (2015). Social fragmentation as a consequence of implementing a Bus Rapid Transit system in the city of Bogotá. Urban Studies, 53(8), 1617-1634. https://doi.org/10.1177/0042098015588739

Bogotá Mobility Secretary. (2011). Encuesta de Movilidad para Bogotá.

Camporeale, R., Caggiani, L., Fonzone, A., \& Ottomanelli, M. (2017). Quantifying the impacts of horizontal and vertical equity in transit route planning. Transportation Planning and Technology, 40(1), 28-44. https://doi.org/10.1080/03081060.2016.1238569 
Cantillo-García, V., Guzman, L. A., \& Arellana, J. (2019). Estrato socioeconómico como variable sustituta del ingreso del hogar en la investigación de transporte. Evaluación para Bogotá, Medellín, Cali y Barranquilla. DYNA; Vol. 86, Núm. 211 (2019)DO 10.15446/Dyna.V86n211.81821 .

Cantillo, V., Amaya, J., \& Ortúzar, J. de D. (2010). Thresholds and indifference in stated choice surveys. Transportation Research Part B: Methodological, 44(6), 753-763. https://doi.org/10.1016/j.trb.2009.12.003

Carruthers, R., Dick, M., \& Saurkar, A. (2005). Public Transport in Developing Countries. Management, $1-2$. https://doi.org/10.1108/9780080456812

Cervero, R., Rood, T., \& Appleyard, B. (1999). Tracking accessibility: Employment and housing opportunities in the San Francisco Bay Area. Environment and Planning A, 31(7), 1259-1278. https://doi.org/10.1068/a311259

Cervero, Robert. (2013). Transport Infrastructure and the Environment in the Global South : Sustainable Mobility and Urbanism. 25(October), 22.

Cervero, Robert, \& Dai, D. (2014). BRT TOD: Leveraging transit oriented development with bus rapid transit investments. Transport Policy, 36, 127-138. https://doi.org/10.1016/j.tranpol.2014.08.001

Cobham, A., Schlögl, L., \& Sumner, A. (2016). Inequality and the Tails: the Palma Proposition and Ratio. Global Policy, 7(1), 25-36. https://doi.org/10.1111/17585899.12320

Consorcio TPD-Epypsa. (2012). Formulación del Plan Maestro de Movilidad del distrito de Barranquilla.

Cowell, F. A. (2000). Chapter 2 Measurement of inequality. In Handbook of Income Distribution (Vol. 1, pp. 87-166). Elsevier. https://doi.org/10.1016/S15740056(00)80005-6

Cui, B., Boisjoly, G., Miranda-Moreno, L., \& El-Geneidy, A. (2020). Accessibility matters: Exploring the determinants of public transport mode share across income groups in Canadian cities. Transportation Research Part D: Transport and Environment, 80, 102276. https://doi.org/10.1016/j.trd.2020.102276

Curl, A. (2018). The importance of understanding perceptions of accessibility when addressing transport equity: A case study in Greater Nottingham, UK. Journal of Transport and Land Use, 11(1), 1147-1162. https://doi.org/10.5198/jtlu.2018.1003

Curtis, C., \& Scheurer, J. (2010). Planning for sustainable accessibility : Developing tools to aid discussion and decision-making. 74, 53-106.

Curtis, C., \& Scheurer, J. (2015). Performance measures for public transport accessibility: Learning from international practice. Journal of Transport and Land Use, 10(1), 93118. https://doi.org/10.5198/jtlu.2015.683

da Gama Torres, H. (2011). Environmental Implications of Peri-urban Sprawl and the Urbanization of Secondary Cities in Latin America.

Dávila, J., Cantillo, V., Arellana, J., Cepeda, L., García, S., Tyler, N., Oviedo, D., Angulo, R., Cantillo, D., \& Ojeda, A. (2017). Inversión en transporte y bienestar Un análisis de Transmetro y las políticas urbanas en Barranquilla, Colombia.

Dayioğlu, M., \& Başlevent, C. (2006). Imputed Rents and Regional Income Inequality in Turkey: A Subgroup Decomposition of the Atkinson Index. Regional Studies, 40(8), 889-905. https://doi.org/10.1080/00343400600984395

Dewita, Y., Yen, B. T. H., \& Burke, M. (2018). Land Use Policy The e ff ect of transport cost on housing a ff ordability : Experiences from the Bandung Metropolitan Area, 
Indonesia. Land Use Policy, 79(September), 507-519. https://doi.org/10.1016/j.landusepol.2018.08.043

Dimitriou, H., \& Gakenheimer, R. (2011). Urban transport in the developing world: A handbook of policy and practice. https://books.google.co.uk/books?hl=en\&lr=\&id=09kM2SfGTwsC\&oi=fnd\&pg=PR1 $\& \mathrm{dq}=$ xavier+Godard,$+2011+$ transportation+urban\&ots=CwBhTBCQig\&sig=u_xnvfh NO4-071q0i9tFIfi-5BQ

EDUBAR S.A. (2012). Estudio Socioeconómico Y Determinación De La Capacidad Del Sector Residencial Del Distrito De Barranquilla Para La Contribución De Valorizaciòn Por Beneficio General. 76.

Eliazar, I. I., \& Sokolov, I. M. (2010). Measuring statistical heterogeneity: The Pietra index. Physica A: Statistical Mechanics and Its Applications, 389(1), 117-125. https://doi.org/10.1016/j.physa.2009.08.006

Falavigna, C., \& Hernandez, D. (2016). Assessing inequalities on public transport affordability in two latin American cities: Montevideo (Uruguay) and Córdoba (Argentina). Transport Policy, 45, 145-155. https://doi.org/10.1016/j.tranpol.2015.09.011

Ferreira, A., \& Papa, E. (2020). Re-enacting the mobility versus accessibility debate: Moving towards collaborative synergies among experts. Case Studies on Transport Policy. https://doi.org/10.1016/j.cstp.2020.04.006

Ford, A., Barr, S., Dawson, R., \& James, P. (2015). Transport Accessibility Analysis Using GIS: Assessing Sustainable Transport in London. ISPRS International Journal of GeoInformation, 4(1), 124-149. https://doi.org/10.3390/ijgi4010124

Foth, N., Manaugh, K., \& El-geneidy, A. (2013). Towards equitable transit : examining transit accessibility and social need in Toronto , Canada , 1996-2006. 29, 1-10.

Gandelman, N., Serebrisky, T., \& Suárez-Alemán, A. (2019). Household spending on transport in Latin America and the Caribbean: A dimension of transport affordability in the region. Journal of Transport Geography, 79, 102482. https://doi.org/10.1016/j.jtrangeo.2019.102482

García-Ayllón, S. (2016). Rapid development as a factor of imbalance in urban growth of cities in Latin America: A perspective based on territorial indicators. Habitat International, 58, 127-142. https://doi.org/10.1016/j.habitatint.2016.10.005

Garza, N., \& Lizieri, C. (2019). An empirical approach to urban land monopoly: A case study of the city of Barranquilla, Colombia. Urban Studies, 56(10), 1931-1950. https://doi.org/10.1177/0042098018781306

Geurs, K. T., \& van Wee, B. (2004). Accessibility evaluation of land-use and transport strategies: Review and research directions. Journal of Transport Geography, 12(2), 127-140. https://doi.org/10.1016/j.jtrangeo.2003.10.005

Gómez-Lobo, A. (2020). Transit reforms in intermediate cities of Colombia: An ex-post evaluation. Transportation Research Part A: Policy and Practice, 132, 349-364. https://doi.org/10.1016/j.tra.2019.11.014

Guzman, L., \& Oviedo, D. (2018). Accessibility, affordability and equity: Assessing 'propoor ' public transport subsidies in Bogotá. 68(June 2017), 37-51. https://doi.org/10.1016/j.tranpol.2018.04.012

Guzman, L.A., Arellana, J., \& Alvarez, V. (2020). Confronting congestion in urban areas: Developing Sustainable Mobility Plans for public and private organizations in Bogotá. Transportation Research Part A: Policy and Practice, 134, 321-335. 
https://doi.org/10.1016/j.tra.2020.02.019

Guzman, L A, Oviedo, D., \& Rivera, C. (2017). Assessing equity in transport accessibility to work and study: The Bogotá region. Journal of Transport Geography, 58, 236-246. https://doi.org/10.1016/j.jtrangeo.2016.12.016

Guzman, Luis A., Oviedo, D., \& Rivera, C. (2017). Assessing equity in transport accessibility to work and study: The Bogotá region. Journal of Transport Geography, 58, 236-246. https://doi.org/10.1016/j.jtrangeo.2016.12.016

Guzman, Luis A, Oviedo, D., \& Bocarejo, J. P. J. P. (2016). City profile: The Bogotá Metropolitan Area that never was. Cities, 60, Part A, 202-215. https://doi.org/http://dx.doi.org/10.1016/j.cities.2016.09.004

Gwilliam, K. (2013). Cities on the move - Ten years after. Research in Transportation Economics, 40(1), 3-18. https://doi.org/10.1016/j.retrec.2012.06.032

Hackl, A. (2018). Mobility equity in a globalized world: Reducing inequalities in the sustainable development agenda. World Development, 112, 150-162. https://doi.org/10.1016/j.worlddev.2018.08.005

Handy, S. (2020). Is accessibility an idea whose time has finally come? Transportation Research Part D: Transport and Environment, 83, 102319. https://doi.org/10.1016/j.trd.2020.102319

Hickman, R., Givoni, M., Bonilla, D., \& Banister, D. (2015). 1 The transport and development relationship. International Handbook on Transport and Development, 1.

Inostroza, L. (2017). Informal urban development in Latin American urban peripheries. Spatial assessment in Bogotá, Lima and Santiago de Chile. Landscape and Urban Planning, 165, 267-279. https://doi.org/10.1016/j.landurbplan.2016.03.021

Inostroza, L., Baur, R., \& Csaplovics, E. (2013). Urban sprawl and fragmentation in Latin America: A dynamic quantification and characterization of spatial patterns. Journal of Environmental Management, 115, 87-97. https://doi.org/10.1016/j.jenvman.2012.11.007

Jaramillo, C., Lizárraga, C., \& Grindlay, A. L. (2012). Spatial disparity in transport social needs and public transport provision in Santiago de Cali (Colombia). Journal of Transport Geography, 24, 340-357. https://doi.org/10.1016/j.jtrangeo.2012.04.014

Jones, Peter, \& Lucas, K. (2012). The social consequences of transport decision-making: Clarifying concepts, synthesising knowledge and assessing implications. Journal of Transport Geography, 21, 4-16. https://doi.org/10.1016/j.jtrangeo.2012.01.012

Jones, PM. (2016). The evolution of urban transport policy from car-based to people-based cities: is this development path universally applicable?

https://discovery.ucl.ac.uk/id/eprint/1502400/

Kloosterman, R. C., \& Lambregts, B. (2001). Clustering of economic activities in polycentric urban regions: The case of the Randstad. Urban Studies, 38(4), 717-732. https://doi.org/10.1080/00420980120035303

Levine, J. (2020). A century of evolution of the accessibility concept. Transportation Research Part D: Transport and Environment, 83, 102309. https://doi.org/10.1016/j.trd.2020.102309

Levy, C. (2013). Travel choice reframed: "deep distribution" and gender in urban transport. Environment and Urbanization, 25(1), 47-63. https://doi.org/10.1177/0956247813477810

Levy, C., Allen, A., Castán Broto, V., \& Westman, L. (2017). Unlocking urban trajectories. In Sustainable Cities in Asia (pp. 7-22). Routledge. 
https://doi.org/10.4324/9781315643069-1

Levy, C., \& Dávila, J. D. (2017). Planning for mobility and socio-environmental justice: The case of Medellín, Colombia. In Environmental Justice and Urban Resilience in the Global South (pp. 37-56). Palgrave Macmillan. https://doi.org/10.1057/978-1-13747354-7_3

Litman, T. (2002). Evaluating transportation equity. World Transport Policy \& Practice, $8(2), 50-65$.

Lucas, K. (2012). Transport and social exclusion: Where are we now? Transport Policy, 20, 105-113. https://doi.org/10.1016/j.tranpol.2012.01.013

Lucas, K., van Wee, B., \& Maat, K. (2016). A method to evaluate equitable accessibility: combining ethical theories and accessibility-based approaches. Transportation, 43(3), 473-490. https://doi.org/10.1007/s11116-015-9585-2

Malekzadeh, A., \& Chung, E. (2019). A review of transit accessibility models: Challenges in developing transit accessibility models. International Journal of Sustainable Transportation, 8318. https://doi.org/10.1080/15568318.2019.1625087

Mertins, G. (2007). Estudios Urbanos -Regionales desde el Caribe: El crecimiento "moderno" espacial- urbano en Barranquilla: ¿Planeación pública-oficial o manejo del sector privado? Memorias: Revista Digital de Historia y Arqueología Desde El Caribe Colombiano, 4(7), 114-128.

Niehaus, M., Galilea, P., \& Hurtubia, R. (2016). Accessibility and equity: An approach for wider transport project assessment in Chile. Research in Transportation Economics, 59, 412-422. https://doi.org/10.1016/j.retrec.2016.05.003

Ono, K., Hiratsuka, Y., \& Murakami, A. (2010). Global inequality in eye health: Countrylevel analysis from the global burden of disease study. American Journal of Public Health, 100(9), 1784-1788. https://doi.org/10.2105/AJPH.2009.187930

Ortúzar, J. de D. (2019). Sustainable Urban Mobility: What Can Be Done to Achieve It? In Journal of the Indian Institute of Science (Vol. 99, Issue 4, pp. 683-693). Springer. https://doi.org/10.1007/s41745-019-00130-y

Ortuzar, J. de D., \& Willumsen, L. G. (2011). Modelling Transport. In Modelling Transport. https://doi.org/10.1002/9781119993308

Oviedo, D., \& Guzman, L. A. (2020). Revisiting accessibility in a context of sustainable transport: Capabilities and inequalities in Bogota. Sustainability (Switzerland), 12(11), 4464. https://doi.org/10.3390/su12114464

Oviedo Hernandez, D., \& Dávila, J. D. (2016). Transport, urban development and the peripheral poor in Colombia - Placing splintering urbanism in the context of transport networks. Journal of Transport Geography. https://doi.org/10.1016/j.jtrangeo.2016.01.003

Palma, J. (2006). Globalizing Inequality: 'Centrifugal' and 'Centripetal' Forces at Work (No. 35). https://doi.org/https://doi.org/10.18356/395c7874-en

Pereira, R. H. M., Schwanen, T., \& Banister, D. (2017). Distributive justice and equity in transportation. Transport Reviews, 37(2), 170-191. https://doi.org/10.1080/01441647.2016.1257660

Ramos, R., Cantillo, V., Arellana, J., \& Sarmiento, I. (2017). From restricting the use of cars by license plate numbers to congestion charging: Analysis for Medellin, Colombia. Transport Policy, 60. https://doi.org/10.1016/j.tranpol.2017.09.012

Rodriguez, C., Peralta-Quirós, T., Guzman, L. A., \& Reyes, S. A. C. (2017). Accessibility, affordability, and addressing informal services in bus reform. Transportation Research 
Record, 2634, 35-42. https://doi.org/10.3141/2634-06

Schubert, H., Caballero Calvo, A., Rauchecker, M., Rojas-Zamora, O., Brokamp, G., \& Schütt, B. (2018). Assessment of Land Cover Changes in the Hinterland of Barranquilla (Colombia) Using Landsat Imagery and Logistic Regression. Land, 7(4), 152. https://doi.org/10.3390/land7040152

Schwanen, T. (2015). Automobility. In International Encyclopedia of the Social \& Behavioral Sciences (pp. 303-308). Elsevier. https://doi.org/10.1016/B978-0-08097086-8.72129-5

Sholomo, A., Blei, A., Lamson-Hall, P., Miller, K., Vasconez, J., Galarza Sánchez, J., Salazar, M. M., \& Caicedo, J. F. (2017). Atlas de expansión urbana Colombia.

Simson, R., \& Savage, M. (2020). The global significance of national inequality decline. Third World Quarterly, 41(1), 20-41. https://doi.org/10.1080/01436597.2019.1662287

Singh, Y. J., Lukman, A., Flacke, J., Zuidgeest, M., \& Van Maarseveen, M. F. A. M. (2017). Measuring TOD around transit nodes - Towards TOD policy. Transport Policy, 56, 96-111. https://doi.org/10.1016/j.tranpol.2017.03.013

Skinner, R. (2004). City profile Bogotá. Cities, 21(1), 73-81. https://doi.org/10.1016/j.cities.2003.10.003

Steel, G., van Noorloos, F., \& Klaufus, C. (2017). The urban land debate in the global South: New avenues for research. Geoforum, 83, 133-141. https://doi.org/10.1016/j.geoforum.2017.03.006

UN-Habitat. (2014). Global Urban Observatory (GUO).

UNDP. (2016). Sustainable Development Goals (SDGs)| UNDP. http://www.undp.org/content/undp/en/home/sdgoverview/post-2015-developmentagenda.html

Uteng, T., \& Lucas, K. (2017). Urban mobilities in the global south. https://books.google.com/books?hl=en\&lr=\&id=z25ADwAAQBAJ\&oi=fnd\&pg=PT2 $2 \& d q=$ transport+planning + global+south+lucas\&ots=4Ac8s4Iryv\&sig=ktwyTw8FAfH Db7DlLi2MlLmcuv4

Uteng, T. P., \& Lucas, K. (2018). The trajectories of urban mobilities in the Global South. In Urban Mobilities in the Global South (pp. 1-18). Routledge. https://doi.org/10.4324/9781315265094-1

van Wee, B. (2011). Evaluating the impact of land use on travel behaviour : the environment versus accessibility. 19, 1530-1533.

van Wee, B., \& Geurs, K. (2011). Discussing equity and social exclusion in accessibility evaluations. European Journal of Transport and Infrastructure Research, 11(4), 350367. https://doi.org/10.18757/ejtir.2011.11.4.2940

Vecchio, G., Tiznado-Aitken, I., \& Hurtubia, R. (2020). Transport and equity in Latin America: a critical review of socially oriented accessibility assessments*. Transport Reviews, 40(3), 354-381. https://doi.org/10.1080/01441647.2020.1711828

Venter, Christo; Mahendra, Anjali; Hidalgo, D. (2019). From Mobility to Access for All: Expanding Urban Transportation Choices in the Global South. www.citiesforall.org.

Venter, C. (2011). Transport expenditure and affordability: The cost of being mobile Transport expenditure and affordability : The cost of being mobile. Development Southern Africa, 28(1), 121-140. https://doi.org/10.1080/0376835X.2011.545174

Watson, V. (2009). "The planned city sweeps the poor away...": Urban planning and 21st century urbanisation. Progress in Planning, 72(3), 151-193. https://doi.org/10.1016/j.progress.2009.06.002 
1 Weiss, D. J., Nelson, A., Gibson, H. S., Temperley, W., Peedell, S., Lieber, A., Hancher, 2 M., Poyart, E., Belchior, S., Fullman, N., Mappin, B., Dalrymple, U., Rozier, J.,

3 Lucas, T. C. D., Howes, R. E., Tusting, L. S., Kang, S. Y., Cameron, E., Bisanzio, D., $4 \quad$... Gething, P. W. (2018). A global map of travel time to cities to assess inequalities in 5 accessibility in 2015. Nature, 553(7688), 333-336.

6 https://doi.org/10.1038/nature25181

7 Woolf, S. E., \& Joubert, J. W. (2013). A people-centred view on paratransit in South

$8 \quad$ Africa. Cities, 35, 284-293. https://doi.org/10.1016/j.cities.2013.04.005

9 Wu, H., \& Levinson, D. (2020). Unifying access. Transportation Research Part D:

Transport and Environment, 83, 102355. https://doi.org/10.1016/j.trd.2020.102355 